\title{
ATTACHMENT AND SEPARATION DISTRESS \\ IN THE INFANT GUINEA PIG
}

\author{
Terry F. Pettijohn
}

\section{A Dissertation \\ Submitted to the Graduate School of Bowling Green State University in partial fulfillment of the requirements for the degree of \\ DOCTOR OF PHILOSOPHY}

December 1974

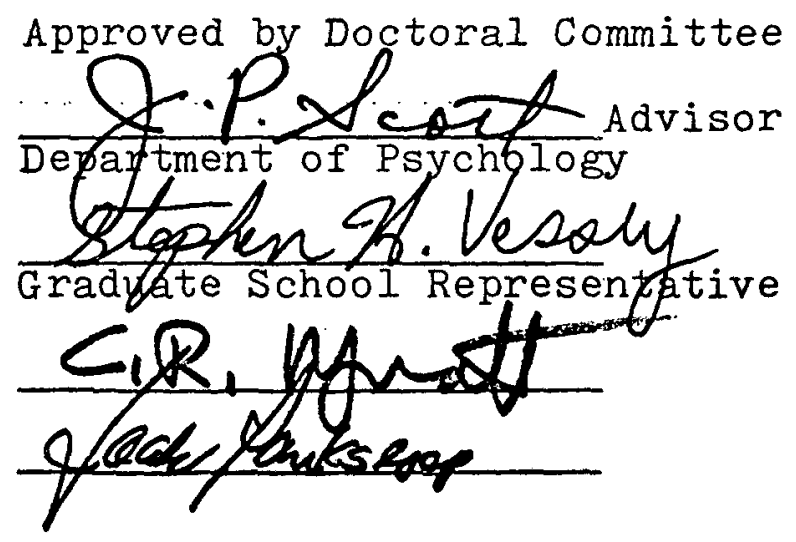

BOWLING GREN SIAEE U.I.ERSITY LIBRARY 


\section{Abstract}

Attachment during the first eight weeks of life in the infant guinea pig was studied through an observation and series of four experiments. Particular attention was placed on evaluating the technique of using separation distress vocalization as the dependent measure.

The observation of home social behavior demonstrated that approach and following behaviors occurred at a fairly stable rate in the home box. Nursing and contact behaviors were frequent during the first four weeks and then rapidly declined. Weaning occurred at four weeks and might influence attachment in the infant guinea pig.

Experiment 1 found that when tested in a two-choice situation, infant guinea pigs spent more time in close proximity to the mother than to the father during weeks 2 and 4 after birth. Experiment $1 \mathrm{~A}$ found that infants reared with the biological mothers and another lactating female preferred the mother only during week 2.

Experiment 2 found that distress vocalization under conditions of maximum separation from familiar surroundings remained high for the first four weeks, and then steadily declined. Habituation effects were not found with testing twice daily during week 5 .

Experiment 3 found that the mother only strongly responded to a recording of infant distress vocalization during week 1 after birth, and the father did not respond at any time.

Experiment 4 measured attachment using separation distress to the social (the mother) and physical environment (the home box) in the infant guinea pig. Results showed that when the mother was present, vocalizations were extremely low, and when she was absent, the vocalization rate was moderate if the subject was isolated in the home box, or high if the subject was in an unfamiliar box. Experiment 4 A showed that social attachment could be generalized to the father and siblings but not to an unfamiliar adult female.

The results using separation distress vocalization agreed with other attachment measures, and hence can be a useful technique for the study of attachment in the infant guinea pig. 


\section{Acknowledgements}

I cannot sufficiently express my gratitude and appreciation to Dr. J. Paul Scott, my sponsor, chairman, teacher and friend. Through word and deed he has giver. me the methods and philosophy of research, knowledge and life. His understanding and helpful advice have dcne much to shape me into a researcher and teacher. My debt is great.

The concern of Dr. Steven vessey for my broadened outlook in research is much appreciated. He greatly contributed to my interdisciplinary approach to animal behavior.

Dr. Jaak Panksepp deserves much credit for the rigorous methodology in my research. I also sincerely thank him for the great help he gave me in revising my many manuscripts. His lessons were well received. The advice and suggestions of Dr. Clifford Mynatt were extremely valuable in improving my communication skills. He greatly helped me appreciate the value of well written research. He also provided a broader interpretation of the work.

The advice and encouragement of Dr. C. Max Freeburne will long be remembered. Although not at my finish, he was of immense help throughout my studies. I owe most of my teaching philosophy and method to him.

Dr. John Schuck had faith in me, and I wish to thank him for this as well as his teachings of methodology and statistics.

I deeply appreciate the patience, love and devotion shown by my wife, Bernadette. She not only motivated and reinforced my efforts, but was responsible for all the editorial advice and typing of the many revisions of the manuscript.

Finally, the birth of our son, Terry Jr., provided the stimulus to complete the task. Without my family, the purpose would not have been alive. 
TABLE OF CONTENTS Introduction. ......................... page

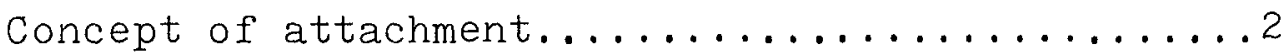

Separation distress in other species..........4

Mother-infant interaction in the guinea pig and

infant distress vocalization................10

Attachment studies using the guinea pig........13

General rationale and plan of the dissertation...18

Subjects and rearing methods.................21

Subjects.......................

Care.........................22

Observation of Home Social Behavior.............24

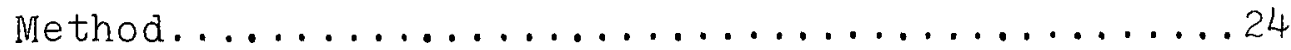

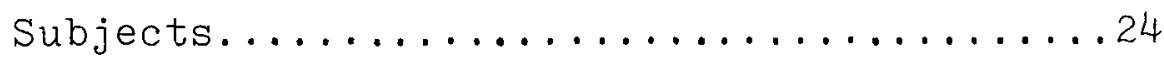

Procedure......................24

Behavior categories..................25

Results.........................26

Discussion........................... 34

Experiment 1. Reaction of the infant guinea pig

toward its parents in a two-choice situation.........36

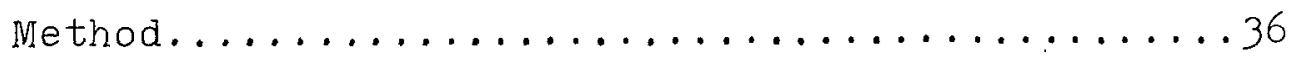

Subjects......................

Apparatus.........................

Procedure.......................... 37

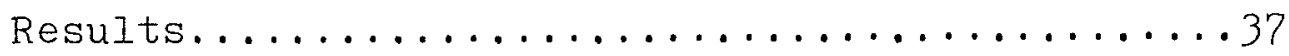


Table of Contents (Cont'd)... page

Discussion..........................41

Experiment $1 \mathrm{~A}$. Reaction of the infant guinea pig to its mother and another familiar adult

female in a two-choice situation...............44

Results and discussion................

Experiment 2. Development and habituation of separation distress vocalization............... 48

Methods..................................

Subjects...........................49

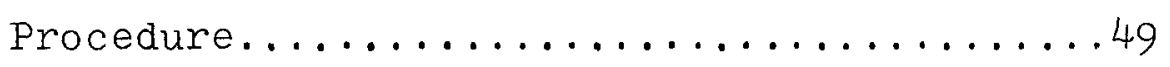

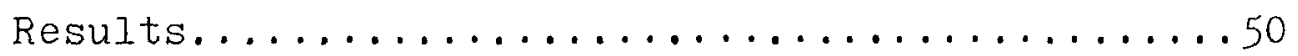

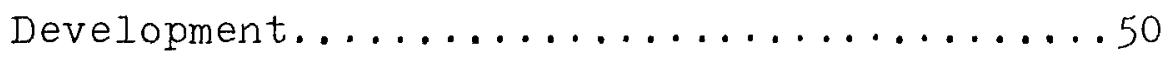

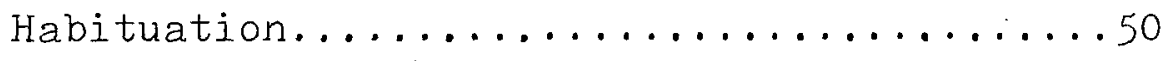

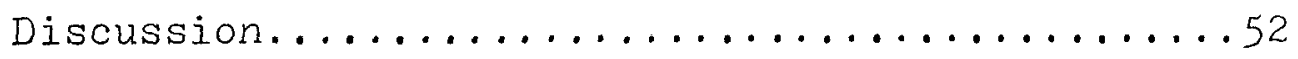

Experiment 3. Reaction of parents to recorded

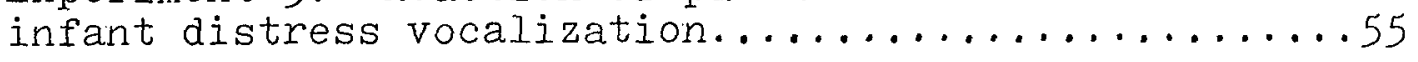

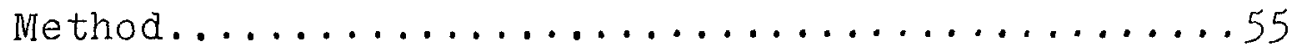

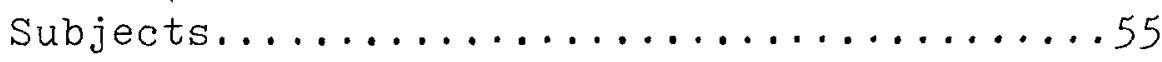

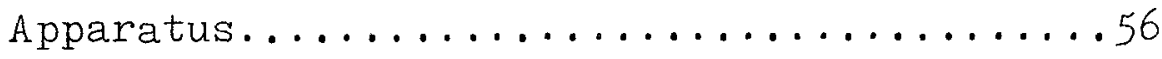

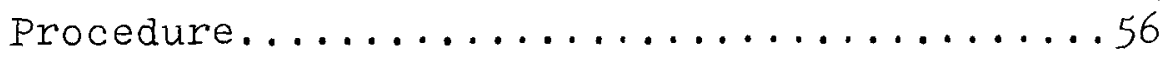

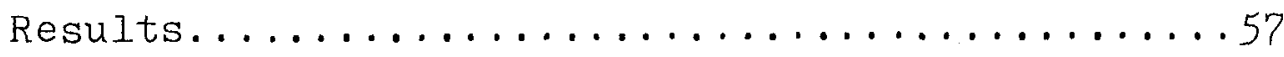

Discussion........................61

Experiment 4. Attachment in infant guinea pigs

as measured by separation distress vocalization......64

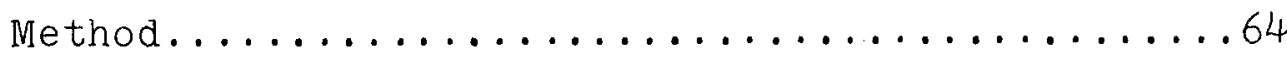

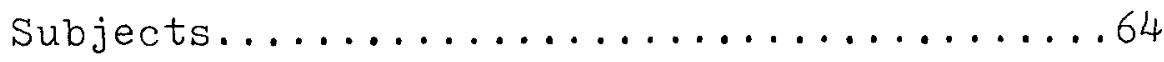


Table of Contents (Cont'd)... page

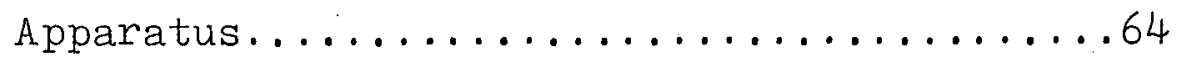

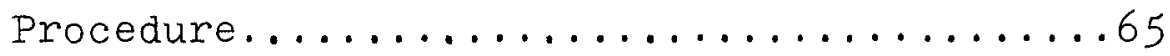

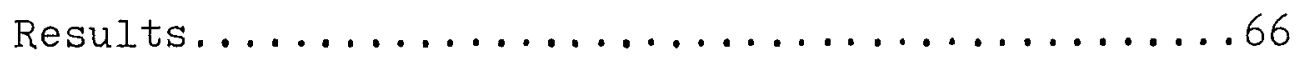

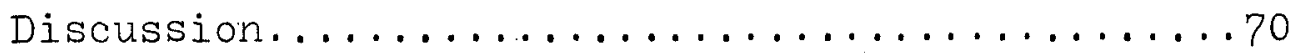

Experiment 4 A. Social attachment variables

and separation distress vocalization.............72

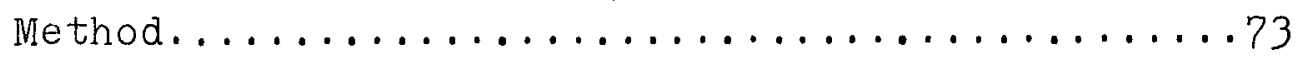

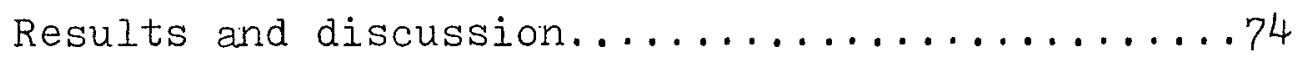

General Discussion........................

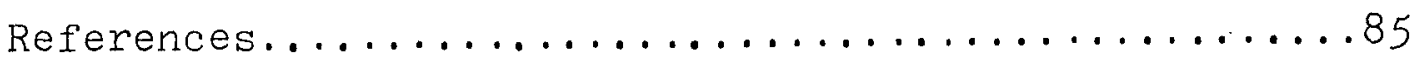




\section{LIST OF FIGURES}

Figure 1.

Page

Home Box with Experimental Modifications........23

Figure 2 .

Percentage of Observation Minutes Which

Contained Nursing Behavior by Infant

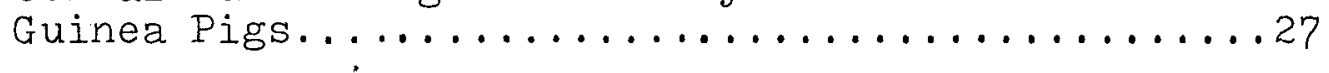

Figure 3.

Percentage of Observation Minutes Which

Contained Contact Behavior by Infant

Guinea Pigs..........................29

Figure 4.

Percentage of Observation Minutes Which

Contained Approach Behavior by Infant

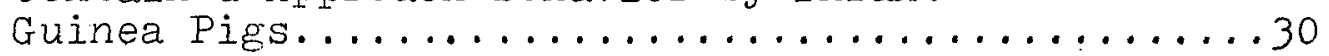

Figure 5.

Percentage of Observation Minutes Which

Contained Following Behavior by Infant

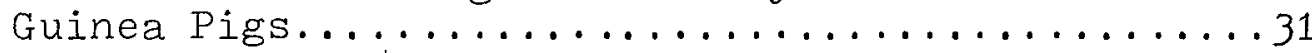

Figure 6.

Amount of Time Infants Spent in Section

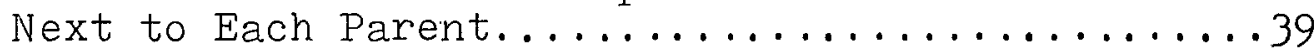

Figure $?$.

Development of Separation Distress

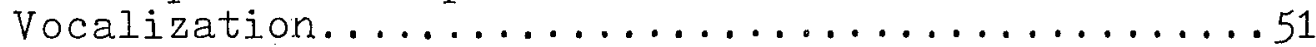

Figure 8 .

Habituation of Separation Distress

Vocalization in Five Week Old Guinea Pigs.......53

Figure 9.

Mean Amount of Time Parents Spent in End

With Sound Source in à Five Minute Period........59

Figure 10 .

Attachment to Social and Physical Envir-

onment as Measured by Separation Distress

Vocalization in Infant Guinea Pigs...........68

Figure 11 .

Attachment to Social Stimuli as Measured

by Separation Distress Vocalization in

Infant Guinea Pigs.....................75 


\section{Introduction}

Many species of animals are capable of forming attachments which aid in survival. The motivational system involved in attachment and separation has not been studied as intensively as other motivational systems, such as sexual, agonistic or ingestive behavior. Some important work has been conducted, but much remains to be done in defining attachment behavior and forming empirically based theories of attachment in a wide variety of animals.

This dissertation examines social and physical environmental attachment during the first 8 weeks of life in the infant domestic guinea pig (Cavia porcellus). Its objectives include: (a) demonstrating that separation-induced distress vocalization can be used as a reliable measure of attachment; (b) determining the relative importance of social and physical environmental variables in the formation of attachment in the infant guinea pig; and (c) comparing the results using the separation distress with other measures of attachment, including the twochoice discrimination test and frequency of approach. In the introduction, the concept of attachment will be reviewed, and some particular measures of attachment formation explored. Next, separation distress vocalization will be examined in other species. Finally, the guinea 
pig literature will be reviewed, with particular emphasis on mother-infant interactions and attachment studies using the guinea pig.

I. Concept of attachment

Attachment behavior includes acts which promote proximity to or contact with the specific attachment object or environment (Ainsworth, 1973). Attachment behavior may include signaling behavior (such as vocalizing), orienting behavior (such as looking), and locomotion (such as following, approaching, and active physical contact). These behaviors help maintain association with the attached environment and prevent separation from it.

A theory of infant attachment based on association was developed by Cairns (1966). According to the theory, strength of attachment is determined by the amount of time the infant spends with the object. The more time spent with an object, the stronger the attachment to it becomes. Aside from sheer exposure, the attractiveness of the object helps determine strength of attachment. Social objects are usually more intrinsically attractive to an animal, thus, social attachment is often very strong. Scott (1971) enlarged on this concept, and proposed an attachment theory in which the basic mechanism is emotional distress stimulated by the absence of the 
familiar environment. As an infant, an animal is distressed when separated from its familiar environment and is rewarded when it is returned. Thus behavior that maintains contact is reinforced both negatively and positively. This hypothesis suggests that separation might be involved in forming attachments to the physical and social environment in which the infant lives. Attachment behaviors can be measured in several ways. Sluckin (1970) has reviewed attachment measurement and has suggested several methods, such as the distressat-separation test, in which the subject is separated from the attachment stimulus and the rate of its distress vocalizations recorded. The higher the rate, the stronger the attachment. Care must be taken, however, to demonstrate unequivocally that distress results from attachment. For example, Zajonc (1972) has pointed out that if an interesting object (but one to which there is no attachment) is removed, the animal should not vocalize. Also, Scott (1971) has shown that distress may be due to presence of the strange as well as absence of the familiar.

A second attachment measure suggested by Sluckin is recognition. Animals which have formed an attachment to a particular object should approach and follow that object more than they would approach and follow a neutral 
object. Most of the work in this area has been with birds, however some mammals have been tested in this fashion. Again, Zajonc (1972) argued that approach behavior may be a misleading measure of attiachment, since animals may approach strange objects while investigating their environment. If contact is not maintained over time, attachment has not taken place. Many studies which used approach and following behaviors as dependent measures did not investigate the naturally occurring frequencies in the species tested. Therefore it would be expected that confounding would occur through the subjects giving natural behaviors in the test situation.

A third attachment measure offered by Sluckin (1970) is a two-choice discrimination test, in which the subject is expected to choose the stimulus to which it is more strongly attached. The criticism here would also be that animals might choose a novel stimulus, so care should be taken to insure that the subject is familiar with both test stimuli. Again many studies which used this method used unfamiliar test stimuli and hence invalidated the results as measurement of attachment. of these three measures of attachment, the distress-atseparation test appears most clear cut in its explanation. II. Separation distress in other species 
Separation distress has been used as a measure of attachment across a wide variety of species. Most of the studies have used distress vocalization as the dependent measure, however some have looked at other behaviors, such as increased activity level or depression. Care must be taken to insure that the distress is only due to separation from the test stimulus. Distress vocalization may also be elicited at the presence of the strange. This, of course, would be due to fear and not attachment. Thus any experiment using separation-induced distress vocalization as a measure of attachment must be careful to see that the home and test situations are identical except for the object to be tested for attachment. When this is done, however, the results are extremely clear cut. No other explanation is possible than that attachment has been formed. Following is a review of studies which have examined separation distress.

Bermant (1963) examined the frequency and intensity of distress vocalization in chickens as induced by varying degrees of social isolation. One week after hatching, he tested ten chicks when they were alone, when they could hear but not see a mother hen, and when they could both hear and see her. He found that the chicks produced both soft and loud distress calls, and the more isolated they became, the higher the frequency of the 
loud and the lower the number of soft calls they produced. Distress vocalization was a successful measure of social attachment for this species.

The duckling has also been examined for distress vocalization upon separation from an attached object. Hoffman (1968) found that after ducklings were imprinted to a moving stimulus, their separation from the stimulus produced distress calls, which immediately terminated when the ducklings were reunited with the attachment stimulus. Hoffman, Barrett, Ratner and Singer (1972) extended this finding and demonstrated that a neutral stimulus could be classically conditioned to become a suppressor of distress calling in ducklings when the neutral stimulus was paired with the imprinted stimulus. The subjects were imprinted on a moving object and then a light was paired with the object. The subjects, after being conditioned, vocalized when the light was removed and became quiet when the light was reintroduced. This suggests that the role of learning in attachment is extremely important and needs much study.

King (1963) reported that young deer mice gave distress vocalizations when removed from their nest. The cause of the distress vocalization was probably discomfort from a drop in temperature, since, if the mice were kept at the same temperature as the home nest, 
they did not vocalize when separated.

Several studies have been conducted in kittens on separation-induced distress vocalization and its alleviation by familiar social or physical surroundings. Rosenblatt and Schneirla (1962) found that kittens which were prematurely separated from their litter and mother before normal weaning produced continuous crying for at least a week. Rosenblatt, Turkewitz and Schneirla (1969) carried out an experiment in which they found that the kitten had lower distress vocalizations when isolated in its home than when it was isolated in an unfamiliar location. Rheingold and Eckerman (1971) conducted a thorough developmental study which investigated the effectiveness of the mother, a littermate, and the home environment in alleviating the distress vocalization elicited by isolating kittens in a strange environment. The strange room was identical to the home room except that it did not have a nest box, sand pan, chair, or food and water dishes. They found that kittens isolated in a strange environment distress vocalized at a high rate. When the mother or a littermate was present, the frequency of vocalizations was reliably reduced throughout the 8 week testing period. When the distressed kittens were alone in the home environment, the cries were not reduced as greatly. Therefore, it was concluded 
that the distress was caused by separation from the familiar and not presence of the strange, and the separation from social stimuli caused more distress than separation from the accustomed physical environment.

In the puppy, Elliot and Scott (1961) demonstrated that separation-induced distress vocalization reliably occurred as early as 3 weeks of age and continued at a high level until about 8 weeks, when it gradually decreased and became less reliable. If the puppies were isolated from their mother and siblings but were in their home pen, the vocalization rate was almost half of what it was if they were isolated in an unfamiliar pen (identical to the home pen). Fredericson (1952) found that the presence of a littermate would reduce the frequency of vocalization by up to 90 per cent. Scott and Bronson (1964) also found the vocalization rate of the isolated puppy was reliably reduced by a companion puppy. Pettijohn, Wong, Ebert and Scott (1974 manuscript in preparation) determined the effectiveness of various stimuli in alleviating separationinduced vocalizations in puppies. They found that the most effective alleviating stimuli were human beings and dogs (social objects), while relatively ineffective stimuli were food and unfamiliar toys (physical objects). Distress vocalization was again a useful measure of 
attachment in this species.

Much work has also been done with the separation response in the monkey. Harlow (1959) found that young rhesus monkeys screamed when isolated in a strange room, but were comforted and spent much of the time playing and exploring when the mother was with them. Jensen and Tolman (1962) also reported that upon separation from its mother, the infant monkey (Macaca nemestrina) showed extreme distress symptoms, including vocalizations. The presence of the mother effectively reduced the frequency of vocalizations to near zero.

Finally, human infants have been shown to produce distress vocalizations when isolated (Rheingold, 1969). As in most of the animal research, Rheingold found that the presence of the mother usually eliminated the infant's cries, even in an unfamiliar'environment. Although humans form attachment to their physical environment, social attachment is much more predominant.

Separation distress vocalization has been shown to be an effective measure of attachment in a wide variety of species. The specific cause of distress was usually easily interpreted. Distress vocalization has never been systematically examined as a measure of attachment in guinea pigs, although several investigators have reported the existence of distress vocalizations when 
infant guinea pigs become separated from their mother.

III. Mother-infant interaction in the guinea pig and infant distress vocalizations

There have been several large-scale observational studies of the social behavior of the guinea pig. Of particular interest here is the information describing the mother-infant relationship, and distress vocalization. Berryman (1970) has described 11 distinct guinea pig vocalizations, including a category of whistle. She reported that young guinea pigs whistled when separated from each other. Berryman reported that adults whistled when food or water was supplied to them. She thought the vocalization was the same in each situation. She showed that structurally, the whistle began with frequencies ranging from $0-3 \mathrm{kc}$, and then rose to frequencies ranging from 8-10 kc. Allen (1904) also noted the whistle distress vocalization in the guinea pig, which he labeled as probably a hunger call. Tobach and Gold (1966) observed that young guinea pigs ( 6 weeks) often vocalized when placed in an open field, while older subjects (1 year) did not. Thus it appears that the distress call of the infant and adult guinea pig has been found in a variety of situations.

King (1956) conducted one of the most thorough investigations of the social relationships of the guinea 
pig (Cavia porcellus) under semi-natural situations. He observed that the mother-infant bond was very strong. For example, the mothers often remained close to their offspring while the infants were being weighed and often went to them when they whistled. However, this response was neither immediate nor reliable, as sometimes the mothers completely ignored their offspring, while at other times mothers became upset if prevented from going to their calling offspring. The et-epimeletic or caresoliciting response was well-developed in the young guinea pig, as demonstrated by the finding that the young often whistled when deprived of their mothers. King found that infant guinea pigs might not whistle when the mother left, but often did when the mother returned, or when they were hungry. The exact ages were not specified, but King reported that when slightly older, infant guinea pigs distress vocalized when alone in an unfamiliar place. If hungry, the young guinea pig whistled in the presence of others until its mother came and nursed it. Like Berryman (1970), King reported that animals of all ages whistled when fed or watered by human caretakers. Thus, King concluded that this vocalization was a general call for attention, with the particular function of signaling distress 
when the infant was separated from its mother.

Kunkel and Kunkel (1964) conducted a thorough study of the maternal social behavior of the guinea pig under laboratory conditions. They reported that the young nursed about 3 weeks, but stayed close to the mother. until sexual maturity, at which time they no longer showed any attraction to her. The infant guinea pigs often vocalized when separated from the mother, and the mother often went to her distressed offspring. Female guinea pigs who had young did not discriminate between their own offspring and others of similar age, as exemplified by the finding that most mothers would react to distress vocalizations of any young.

A third large scale study of guinea pigs was conducted by Rood (1972) on the behavior of three genera of Argentine cavies. Of particular interest is his comparisons with Cavia aperea, a wild relative of the domestic guinea pig (Cavia porcellus). Rood found that the Cavia aperea were normally silent, while the guinea pig (Cavia porcellus) vocalized a great deal. In one experiment, he recorded vocalizations of four domestic guinea pigs when each was contained separately in a wire trap in the home pen. He found that vocalizations were low and that they decreased from the first week to 
the fourth and eventually disappeared, due to familarization. Low vocalization rates would be expected since the subjects were not totally separated from either social or physical surroundings. Rood noted that domestic guinea pigs often whistled, which he felt indicated excitement or arousal (and in the young, anxiety). Young domestic guinea pigs often whistled when placed in an unfamiliar situation or when they were away from their mothers, although lactating females often completely ignored the vocalizing offspring. Rood also considered the distress vocalization of the young to be similar to the call given by the adult guinea pig when it was being fed. Another species difference was that nursing by domestic guinea pig females tended to be indiscriminate, while Cavia aperea females almost always rejected any young which were not their own.

The studies which examined the mother-infant interaction in the guinea pig generally found that vocalization was important in maintaining contact between the mother and her offspring. Attachment in the guinea pig has been studied through several other measures, which will be reviewed next.

IV. Attachment studies using the guinea pig Hess (1959) was the first to note that very young pigs would imprint on a moving stimulus and follow it at 
a later time. Shipley (1963) also found that guinea pigs would follow a moving object, particularly if exposed to the object early in life. Sluckin (1968) argued that a discrimination test would be a better test of attachment than just approaching or following. He thus removed guinea pigs from their mothers at 5-7 days of age and exposed them for one hour a day to either a moving cube or ball for 4 days. Then he tested them the following day in a two-choice situation with the cube and the ball. The subjects significantly chose the stimulus to which they had been exposed over the alternative.

In another experiment, Gaston, Stout and Tom (1969) removed infant guinea pigs from mothers at birth and exposed them to one of several objects in a circular runway during the first day of life. They found that all 18 subjects followed the stimulus, and preferred it to competing stimuli in a choice test. When allowed to remain with their mothers, however, the following response was greatly impaired, thus suggesting a relatively weak attachment to the test stimulus.

Another study of early attachment in guinea pigs was conducted by Harper (1970), who investigated the influence of sound and contact on the social preference of the infant guinea pig in a T-maze (with a moving model or mother in one goal box and the other goal box 
empty). For subjects isolated at birth, exposure to a vocalizing, furry, moving model for the first 3 days of life was enough to reinforce maze running behavior 5 days later. In another test, a vocalizing model was approached more often that a silent one, and a soft model kept the subject contacting it for longer periods of time. Subjects which were exposed to a model still responded to it after 7 days experience with the real mother. However, like Gaston et al. (1969), Harper found that early experience with the mother tended to decrease effectiveness of the model. Caution must be taken in assuming these results indicate attachment, since the possibility exists that infant guinea pigs might approach and contact any. stimulus, particularly if it is vocalizing or moving.

Nagy and Misanin (1970) measured attachment in the guinea pig with a tilt cage, placing a guinea pig in one end and leaving the other end empty. At 135 days of age, subjects which had been communally reared spent more time in the end with a guinea pig than the empty end. Presence or absence of mother in rearing had little effect. As in Harper's (1970) study, it must be assumed that spending time in the guinea pig end of the cage implies attachment and not just curiosity.

Sluckin (1968), Gaston, Stout and Tom (1969) and 
Harper (1970) all investigated extremely young animals. Beauchamp and Hess (1971) examined the long term effects of social and sexual imprinting in the guinea pig. They removed neonates from their mothers in the first day of life and reared them with either a chicken, a nonlactating female adult guinea pig or their real mother and siblings. They were tested weekly for the first 5 weeks and later at week 7 in a discrimination task between an unfamiliar chicken and guinea pig. For the first 3 weeks, the subjects preferred the species with which they were reared. Later, females chose randomly, while males consistently chose guinea pigs. In male sexual behavior tests conducted at 10 and 17 weeks, all subjects preferred female guinea pigs. These findings appear to indicate that imprinting in the guinea pig is not strong, and does not last long. However, some factor seems to be motivating the guinea pig to move towards another guinea pig in a social situation. other studies also indicate that normal adult sexual behavior develops irrespective of rearing condition. Stein and Hoffman (1970) isolated five female guinea pigs at birth, and showed that at maturity they mated and displayed completely normal maternal behavior. Harper (1968) isolated males and females at birth and tested them at 80 days of age. All animals showed 
normal social and sexual behavior. These findings suggest that the guinea pig, unlike some other animals, does not need social interaction for development of normal adult behavior.

Recent evidence suggests that, as with sexual preference behavior, guinea pigs show normal olfactory preference regardless of early experience. Carter and Marr (1970) reared infants and their mothers with either acetophenone, ethyl benzoate, or natural odors. "When tested in a two-choice discrimination task at 3 weeks of age, they preferred the rearing odor, but by 60 days of age nearly all subjects chose the natural odor when tested. Carter (1972) later reared guinea pigs with the same odors as the 1970 study and when tested the subjects did not show strong preferences, however, males tended to be more easily imprinted than females. Again, a two-choice test was used and thus one odor might have been chosen for its novelty.

Several recent studies have examined mother-infant attachment behavior. Porter, Fullerton and Berryman (1973) tested infant guinea pigs in a two-choice discrimination task for either their own mother or another lactating female (with whom they had also been housed). The infant guinea pigs showed no preference. Mothers, however, preferred their own litter to another of the 
same age. The authors concluded that the mother actively controls mother-young interactions in the guinea pig. Fullerton, Berryman and Porter (1974) found that infants were more often observed to nurse and remain in proximity to their biological mother as opposed to another lactating female with which they were also housed. However, when the infants were isolated for a short period of time and returned, their behavior tended to be indiscriminant. The adult females again preferred their own young to that of the other mother. Porter, Berryman and Fullerton (1973) found that infant guinea pigs showed a higher exploration rate when their mother and siblings were present (although confined). The authors reasoned that this result might be explained by the assumption that it would only be advantageous for the young to explore when the mother was present. However, the mother might also serve as added stimulation.

V. General rationale and plan of dissertation

From the attachment studies using the guinea pig, it can be concluded that the infant guinea pig shows a strong following response and can be readily imprinted on a wide variety of stimuli, both social and physical. However, all of the studies which examined long term effects of early exposure found that the attachment response to artificial stimuli rapidly declined. All 
of the studies reviewed used either a discrimination task or looked at following and approach behavior. None of the studies used distress vocalization in reaction to separation as a measure of attachment.

Because the infant guinea pig readily vocalizes when it is separated from its familiar surroundings, it should make a useful subject to investigate attachment using separation distress vocalization as the dependent measure. The present dissertation explores this possibility, as well as compares these results to other measures of attachment. Following is the general plan for conducting the observation and four experiments of which the dissertation is comprised.

The Observation of Home Social Behavior was carried out on eight litters of guinea pigs living with their parents. A basic description of social interaction within a litter of guinea pigs was a necessary preliminary study and could help explain and evaluate results which would be obtained in the experiments in the dissertation. Since approach and following have been used to measure attachment in guinea pigs, these behaviors were recorded as they occurred in the home box. Nursing, contact, grooming, eating, and agonistic behaviors were also noted.

Experiment 1 examined the reaction of the infant 
guinea pig toward its two parents in a choice situation. This experiment was conducted in order to compare previous studies which used the mother as a stimulus, and to use the results to evaluate the findings of other experiments in this dissertation.

Experiment 2 examined the development and habituation of distress vocalization in the guinea pig under conditions of maximum separation from its surroundings. Although many reports of distress vocalizations have been made, no one has systematically examined separation distress vocalization in the guinea pig. This information was needed before distress vocalization was used as a measure of attachment.

Experiment 3 examined the reaction of the mother and the father to tape recordings of distress vocalizations of non-related infant guinea pigs and of white noise. Conflicting reports have been made concerning maternal responsiveness to distressed infants, and therefore these results might help explain parental attachment to infant guinea pigs.

Experiment 4 was considered the most important one of the dissertation. In it the two major categories of objects to which attachment may be made (social and physical environment) were studied by measuring separation distress vocalizations. Two specific variables 
were manipulated: (a) presence or absence of the mother (social environment), and (b) presence or absence of the home box (physical environment). The development of distress vocalization was recorded over the first 8 weeks of life, and sex differences were investigated. The mother was chosen as the social stimulus because it was thought that she would be most likely to have formed an attachment with the subject.

\section{Subjects and Rearing Methods}

Subjects

The animals used for all parts of this dissertation were born and reared at the Bowling Green State University Psychology Department. The original domestic guinea pigs (Cavia porcellus) were obtained from a heterogeneous breeding stock. They were supplemented on several occasions by additional animals obtained from local pet stores. Inbreeding was kept to a minimum to insure greater fertility and health. The size of the breeding colony was maintained at about 50 animals ( 40 females, 10 males), with about 20 young at any one time. Most subjects were short-haired, multicolored animals, easily identified as individuals. Each subject was assigned an identification number when it was born. The 20 subjects used in the distress vocalization development and habituation study were run first. Subjects used for 
the remaining parts were sometimes used in more than one experiment.

Care

Most animals were reared in 0.25 inch plywood boxes $(60 \times 90 \times 30 \mathrm{~cm}$.$) painted with non-lead white on the$ inside, with black vertical lines dividing the walls into $30 \mathrm{~cm}$. sections. Figure 1 illustrates the resulting sections in the box, as well as modifications for the various experiments. Hardwood chips obtained from Carworth Co. were used as bedding, which was changed weekly (every Friday after testing was completed). Fresh water was supplied daily in water bottles hung on a wall of the box. A constant supply of Wayne Guinea Pig Chow and Wayne Lab Chow was available in dishes placed in the center of the box. Crystaline Vitamin $C$ was added to the water supply twice weekly, and lettuce, bread, potatoes, carrots or other vegetables were fed twice weekly. The light cycle was 12-12 (lights on at 8 a.m.). In the breeding boxes, one male was usually housed with three females. When a female was 6 weeks pregnant the other two females were removed from that box. The temperature was maintained at about $75^{\circ}$ Farenheit. AII animals were reared in the same room, and thus could hear and smell other conspecifics. 


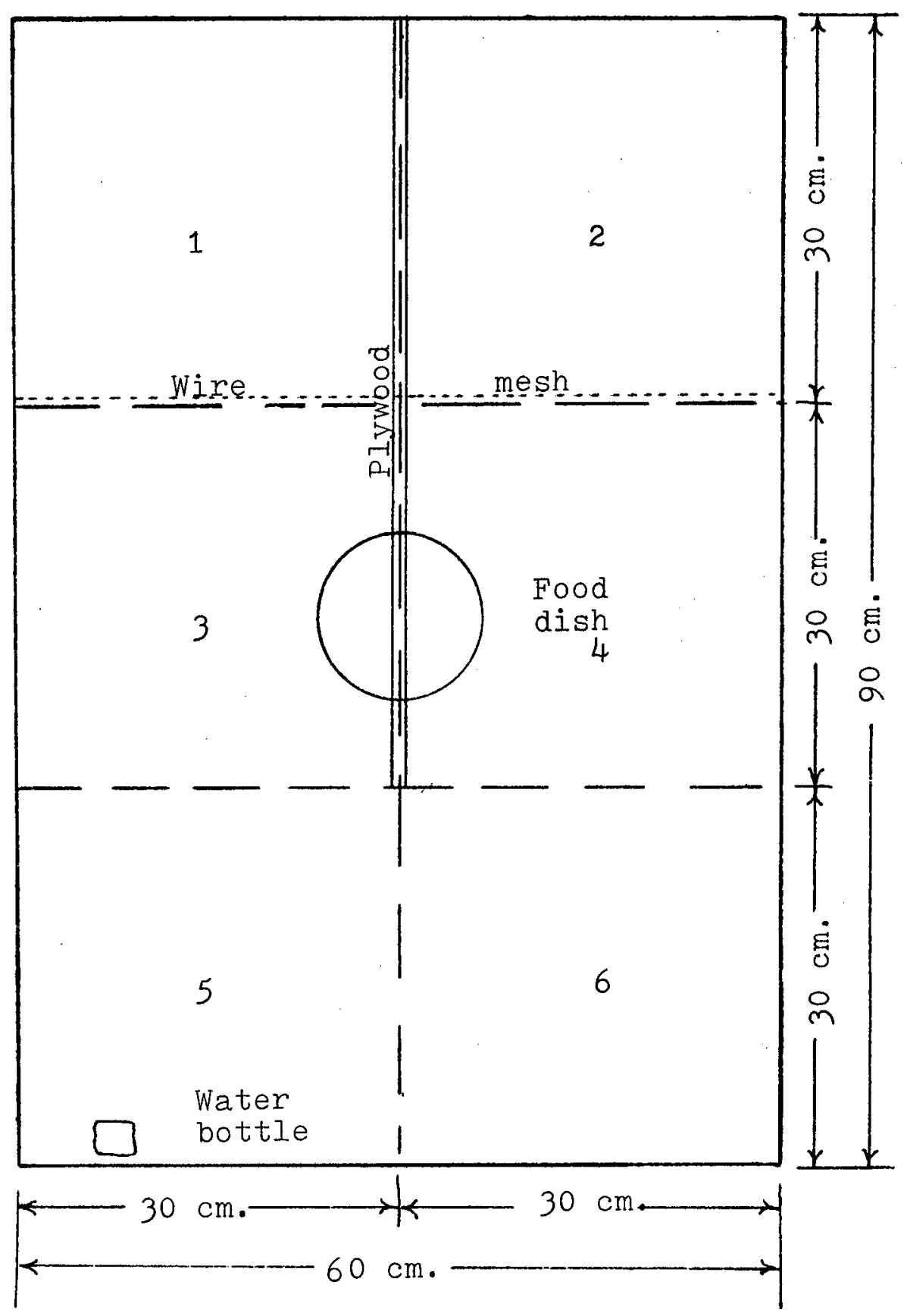

Figure 1. Home box with experimental modifications. 


\section{Observation of Home Social Behavior}

Nethod

\section{$\underline{\text { Subjects }}$}

Twenty-four young guinea pigs from eight litters were observed with their parents to obtain a basic description of social behaviors exhibited by infant guinea pigs. One litter contained six pups, four litters contained three pups each, and three litters contained two pups each. Twenty adult animals (five groups, each consisting of one male and three females) were each observed once in order to determine levels of behaviors in organized groups of adults.

\section{Procedure}

The observations were made in the mornings, prior to any other experiments. Observations of the litters were made Monday, Wednesday and Friday of each week during the 8 weeks after birth.

Observations were made of the litters in their home box, without disturbing any of the animals. The observer stood next to one end of the box and recorded data on a behavior check list for each subject and parent for 5 minutes (divided into minute intervals). A modified time sampling technique was used; whenever an individual engaged in a behavior within a minute interval, that interval was checked. Thus each subject could have a maximum score of 


\section{5 for each week.}

\section{Behavior categories}

The recording check list which was used to score the data contained 11 possible distinct behaviors, defined as follows. "Approach" referred to the situation that occurred when one subject came near a stationary subject. "Follow" occurred when one subject moved in the same direction and at the same speed as another subject. "Contact" was defined as the physical touching of two subjects. "Grooming" referred to the care-giving behavior of the mother to her offspring. "Nursing" occurred when the infant was suckling on the mother. "Play" behavior was defined as the situation in which an animal briskly hopped about, often changing direction in mid air. "Agonistic" behavior occurred when two animals showed conflict behavior. Agonistic behavior was broken into subcategories of attack, retreat, and bite. "Sexual" behavior was defined as any behavior which could lead to copulation. Courtship by the male. was the chief subcategory. "Ingestion" occurred when an animal attempted to ingest food material. Two subcategories were eating and drinking. "Freezing" behavior occurred when an animal became and remained motionless after presentation of a stimulus for at least 30 seconds. "Elimination" consisted of urinating or defecating. 


\section{Results}

The social behavior of a litter of guinea pigs was not as diverse as had been expected. Many of the behaviors were scored only a few times, and only four behaviors of infant guinea pigs occurred with any regularity: nursing, contact, approach and follow.

The occurance of nursing behavior is shown in Figure 2. Since the size of the litters differed, the score for subjects in each litter size was graphed separately. The scores represent the mean per cent of observation minutes in which a subject was observed to engage in the behavior. In week 1 , subjects in all litter sizes showed much nursing behavior, ranging from 77 per cent for the largest litter to 54 per cent for the three litters containing two pups. The percentage for subjects in the litter of six increased slightly in week 2 , while the percentages for subjects in the other litters remained at about the same level. Between weeks 3 and 5, the percentages for subjects in all litters decreased dramatically and thereafter approached zero. There was much variation between subjects in litters of identical size, as indicated by the finding that one mother in a two pup litter nursed only until 4 weeks, while another was observed nursing once during week 6 . However, most subjects were weaned during the fourth 


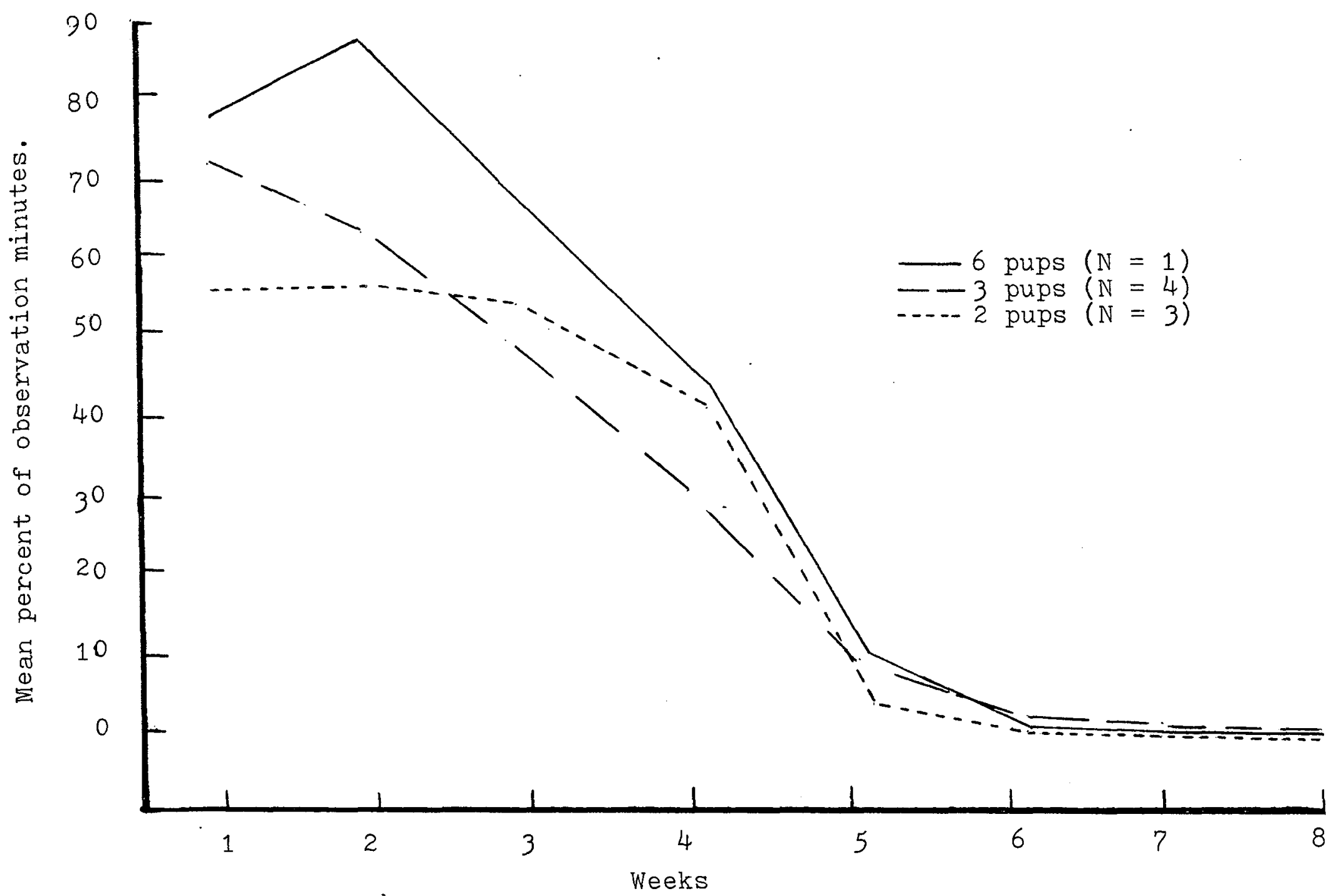

Figure 2. Percentage of observation minutes which contained nursing behavior by infant guinea pigs. 
week after birth, and this pattern was generally repeated in litters of all three sizes.

The per cent of times in which contact behavior by infant guinea pigs was recorded is shown in Figure 3. Again, the different sizes of litters are shown separately. The scores represent the contact of an infant guinea pig with either another infant or a parent. The parent's scores are not shown. In general, the results are similar to nursing behavior, starting at about 70 per cent in week 1, and dropping rapidly over the next few weeks. The scores decline to about 20 per cent for weeks 5 through 8 , as opposed to 0 per cent for nursing behavior. The results for all three litter sizes were quite similar.

The per cent of observation minutes containing approach behavior is shown in Figure 4. The scores are for infant guinea pigs approaching either other infants or parents. The scores remained fairly stable throughout the 8 weeks of observation, with about 30 per cent of the time containing some approach behavior, falling slightly in the final weeks.

Figure 5 shows the per cent of observation minutes containing following behavior of infant guinea pigs in home box observations. Again, the scores remained fairly stable, beginning at about 40 per cent in week 1 


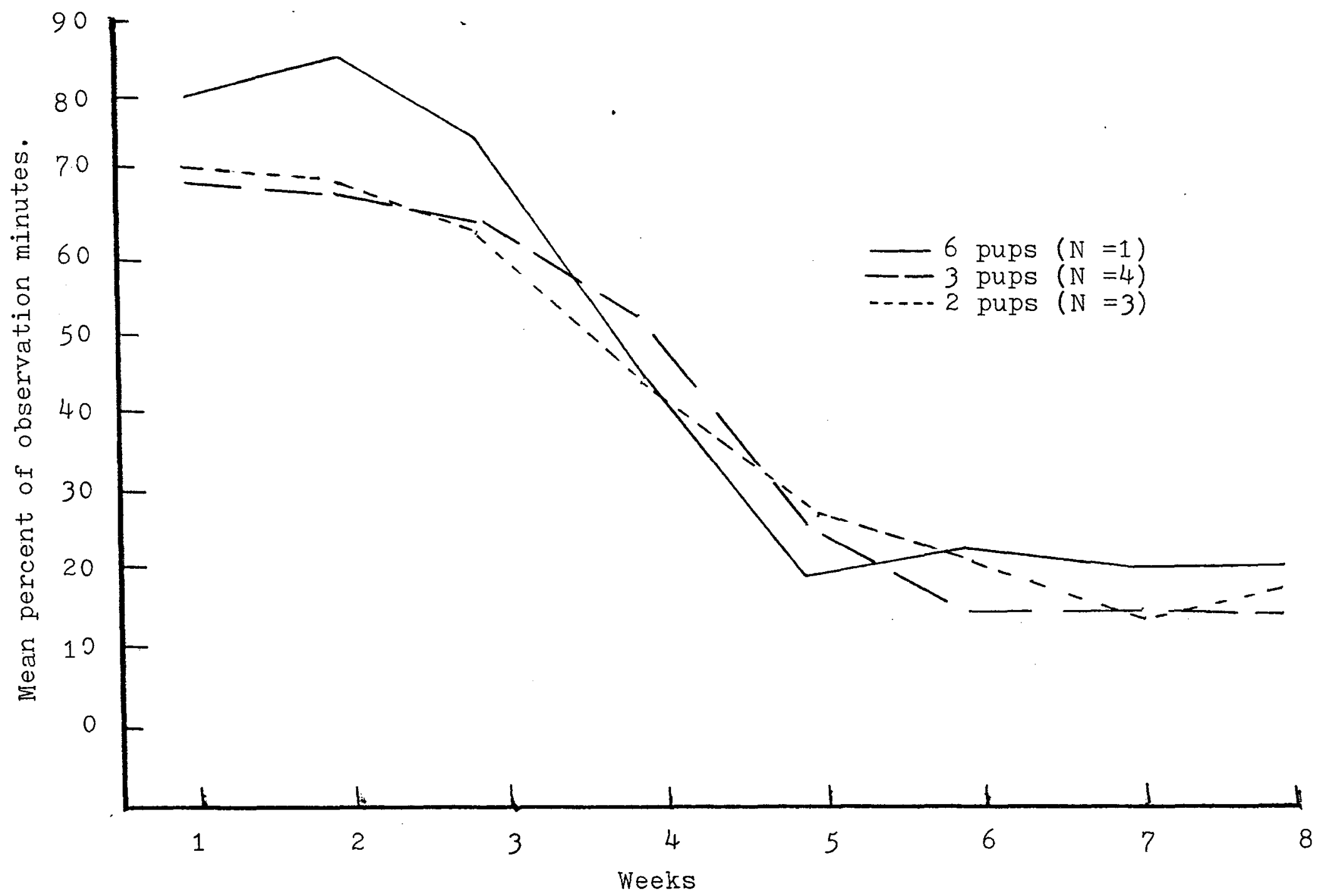

Figure 3. Percentage of observation minutes which contained contact behavior by infant guinea pigs. 


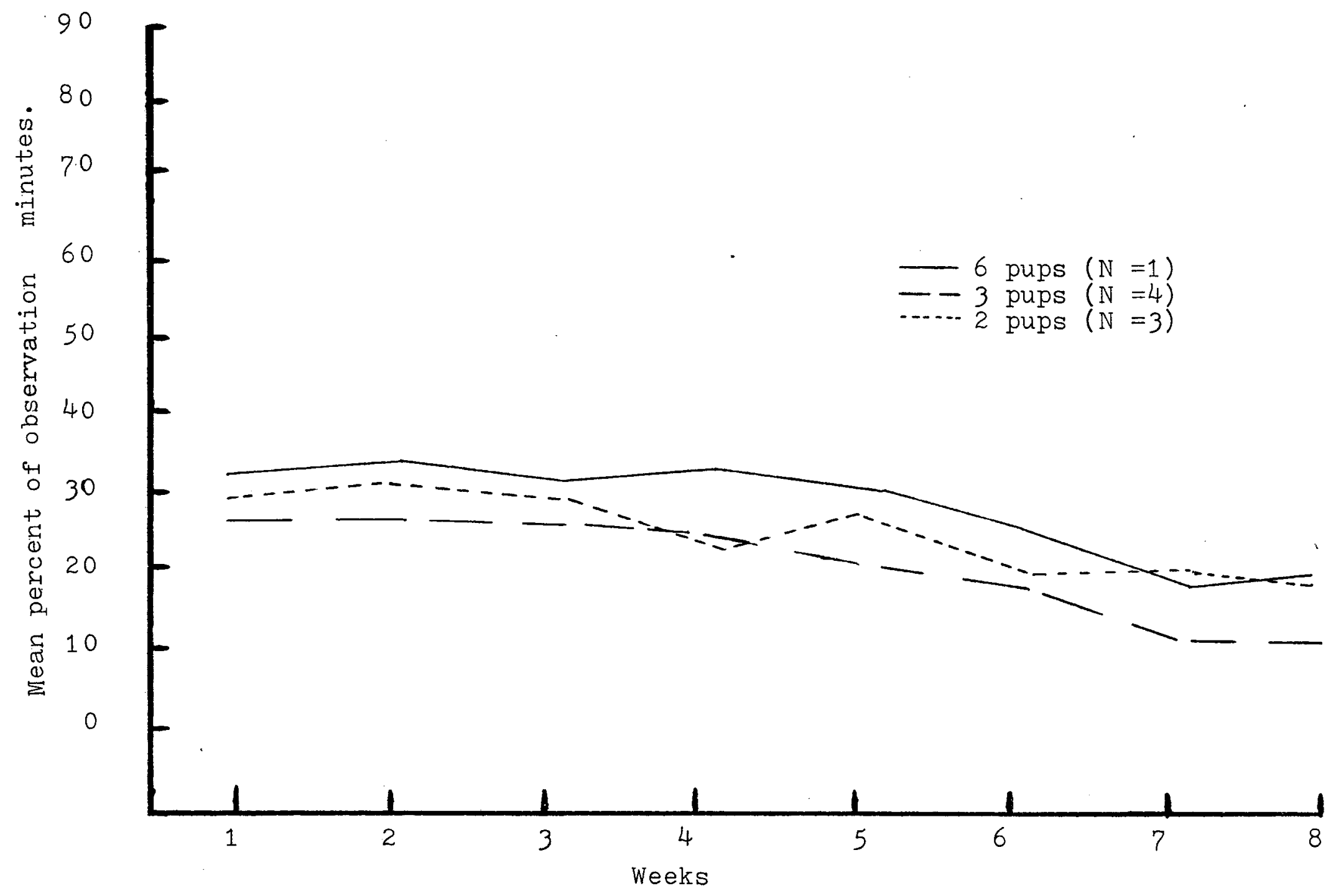

Figure 4. Percentage of observation minutes which contained approach behavior by infant guinea pigs. 


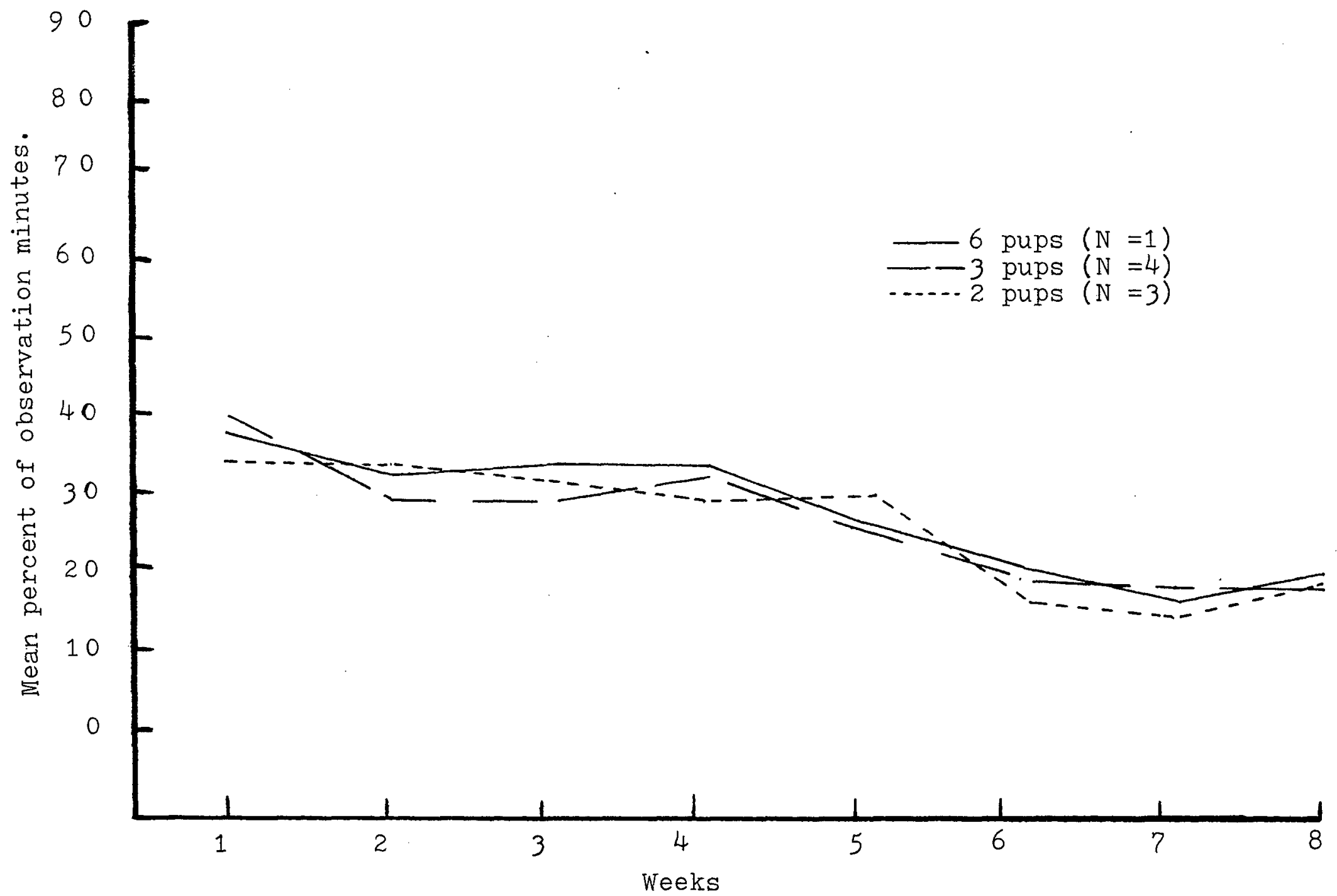

Figure 5. Percentage of observation minutes which contained following behavior by infant guinea pigs. 
and declining to around 20 per cent in week 8 . All litter sizes reacted similarly.

Grooming behavior, in which the mother licked her offspring to clean them, occurred very infrequently, and only in the first 2 weeks after birth. About 15 per cent of the observational minutes contained grooming by the mother of her offspring the first week. This diminished to only about 5 per cent the second week, and then dropped out completely by the third week. Litter size did not make a difference in the amount of grooming time by the mother.

Play behavior by the infant was recorded at a very low rate. It was seen only a few times up to about the third week, when it increased slightly to about 4 per cent. It remained at this rate or lower for the rest of the observation time.

Agonistic behavior among the infant guinea pigs was nonexistent. Between parents, the mother occasionally attacked the father when he got too close to the litter. This behavior only occurred during the first 4 weeks when the mother was nursing her offspring.

Sexual behavior among the infant guinea pigs was also nonexistent for at least the first 7 weeks. During the eighth week, a few observations were recorded of mounting attempts in the young male subjects. The 
father exhibited much courtship behavior during the first few days after birth, when the mother was in estrus. After this time, very little sexual behavior was seen between parents. The father did attempt some courtship with the young during the ejghth week, but it was minimal.

Eating behavior was high for the parents, and developed rapidly in the infants. All infants were recorded eating within the first several days of Iife, and the amount of time spent eating solid food increased until it leveled off at about 4 weeks, at which time they were weaned from the mother. Most individuals ate during about 30 per cent of the observational minutes. Drinking was dependent upon the experimenter. When fresh water was placed in the water bottle, all the animals drank and played with the bottle until the water was gone, usually in a fairly short time. Because the observer did not want to bias the home box behavior, the water bottle was not filled until after the daily observation had been made.

The five groups of four adult guinea pigs which were each observed once as a control showed little social behavior of any kind. Following behavior occurred in about 11 per cent of the observation minutes, approach behavior occurred in about 7 per cent, and contact behavior in 1 per cent. Freezing behavior occurred in 
about 13 per cent of the observation minutes, and eating behavior occurred in about 20 per cent of the time. Other behaviors did not occur with any regularity. One male showed courtship behavior toward one female during the observation of one group.

\section{Discussion}

The scores for nursing behavior tend to support the results of Stern and Bronner (1970), who observed that litters containing four pups nursed about 90 per cent of the observational time in week 1 , while litters containing three, two or one pups nursed less in proportion to the size of the litter. By the fourth week, all litters, regardless of size, nursed about 20 per cent or less of the time. Similar results were also obtained by Stern and Hoffman (1970). It was hypothesized that the large litter subjects nursed more because they obtained less milk during each nursing period, possibly because the mother has only two nipples. Read (1912) investigated the quality of guinea pig milk and concluded that the infant must start eating solid foods early because the mother's milk is low in essential nutrients.

The scores for nursing and contact behavior were similar. The high contact scores were in part due to the nursing situation, however, the contact behavior 
remained fairly high even after nursing behavior ceased. Contact may play a role in infant guinea pig attachments.

The follow and approach scores of the infant guinea pigs did not specify whether the behaviors were directed toward a parent or another sibling. Notes taken during the observations show that during the first 4 weeks, almost all infant follow and approach behaviors were directed toward other infants or the mother, and during the last 4 weeks, the behaviors were also directed toward the father, although at a much lower rate than to the mother or littermate.

The results of the home box social behavior indicate that social interactions occur at a low rate in an established group of adult guinea pigs. This is in marked contrast to the behavior which is observed when strange adult animals are placed together. In this situation, sexual, agonistic and investigative behaviors all rise significantly.

The results showed that many of the behaviors commonly assumed to measure attachment behavior were present in litters of infant guinea pigs raised in a small area. Approaching, following, and contact behaviors all occurred at relatively high levels, suggesting that the infant guinea pig might form strong social attachments. However, the attachments might not carry over into adult- 
hood, as indicated by the low scores on these behaviors in the observations on the groups of adults. This is an area which needs further information on social organization from the natural habitat of the guinea pig.

\section{Experiment 1}

Reaction of the infant guinea pig toward its parents in a two-choice situation

In order to evaluate separation distress vocalization as a measure of attachment, results were first obtained by using another accepted indicator of attachment in guinea pigs: the two-choice discrimination task. Experiment 1 was designed to examine attachment in the infant guinea pig as measured by behavior toward its parents in a two-choice situation.

Method

Subjects

Twenty-four infant guinea pigs which were described in the Observation of Home Social Behavior served as subjects. Twelve males and twelve females from eight litters were tested, with testing starting during the second week of life.

\section{Apparatus}

The subjects were tested in a clean, unfamiliar box of the same dimensions as the home box. It contained bedding, but no food or water, and was located in the 
colony room. The test box was modified as shown in Figure 1 by placing a $30 \times 60 \mathrm{~cm}$. piece of one-inch white plywood midway between the two sides of one end of the box. The plywood extended two-thirds of the length of the box, ending so that sections 5 and 6 were not included in the bisection. Wire mesh was placed so as to create two compartments $30 \times 30 \mathrm{~cm}$. (sections 1 and 2 in Figure 1) at one end of the box.

\section{Procedure}

Each subject was tested on Wednesday of weeks 2, 4, 6 and 8 after birth. Testing was usually carried out in the morning. The subject's mother and father were each randomly placed separately in one of the end compartments. After one minute had elapsed, the subject was placed at the opposite end of the box, facing the end of the dividing piece of plywood.

Observations were recorded for 5 minutes. The main dependent measure was the number of seconds spent in the section closest to each parent (sections 3 and 4 ). o,ther behaviors, including distress vocalization, were recorded using the behavior code sheet described in the Observation.

\section{Results}

The infant guinea pigs appeared noticeably disturbed when first placed in the test box. They vocalized vis- 
ually exploring their new surroundings. After a short while, they usually approached one of the parents and stopped vocalizing. Some would remain near the first parent they had approached, but more often they remained active and moved about the box, approaching both parents several times.

Figure 6 shows the amount of time the infant guinea pigs spent in the section closest to each parent. Because sex of the subject was found to be a nonsignificant variable, the scores of both sexes were combined. Since there were four sections in which the subjects were able to move about in, it was hypothesized that if responding was random, the animals should have spent about 25 per cent of the time ( 75 seconds) in each section. As shown in Figure 6, the subjects did not differ from random behavior with regard to the father, but did spend more time close to the mother in weeks 2 and 4 than would be predicted if they were randomly responding.

A Chi-square test was run for each week on the frequency of subjects who spent the most time in each of the four sections. The scores for weeks 2,4 , and 6 were all significant at the $\underline{p}<.01$ level. Next a Chi-square test was carried out for each week on the frequency of subjects who spent more time in the section next to the mother versus the section next to the father. During 


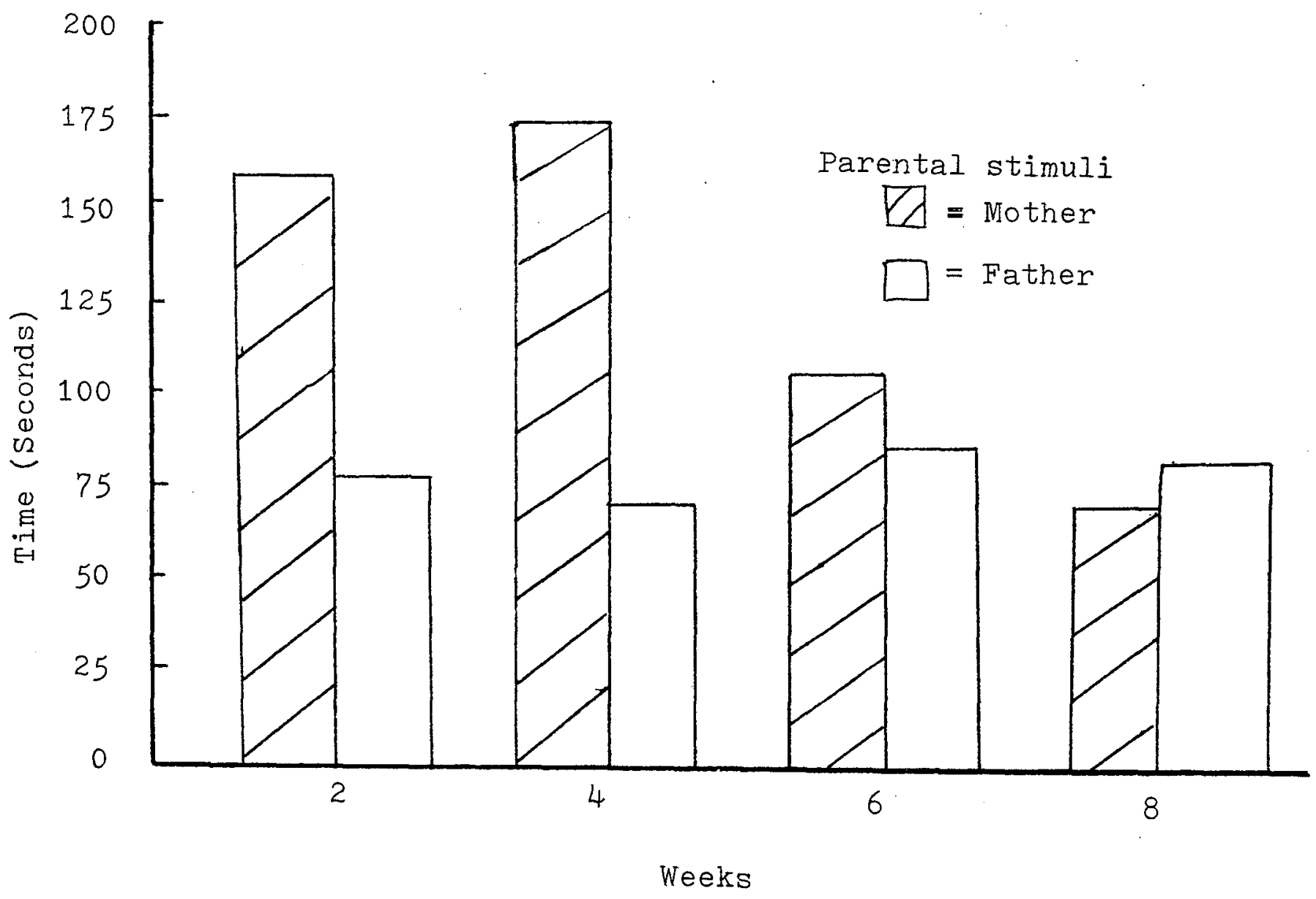

Figure 6. Amount of time infants spent in section next to each parent. 
week 2, 19 subjects spent more time with the mother $\left(x^{2}(1)=8.16, p<.01\right)$. During week 4,21 subjects spent more time with the mother $\left(X^{2}(1)=13.5, \mathrm{p}<.01\right)$. Chi-square tests on the frequency of subjects who spent more time with a parent for weeks 6 and 8 were both nonsignificant. During week 6,15 subjects spent more time with the mother $\left(X^{2}(1)=1.50\right.$, n.s.). During week 8 , 11 subjects spent more time with the mother $\left(x^{2}(1)=.17\right.$, n.s.). This agrees with Figure 6 in which for weeks 6 and 8 the time spent with each parent was similar and not too deviant from the predicted 75 seconds.

Although the time spent next to the father remained fairly constant across time, the total time spent next to any parent declined over weeks. The mean time spent in either section closest to a parent was $115,117,103$ and 83 seconds for weeks 2, 4, 6 and 8 respectively. A Chi-square test was carried out for each week on the frequency of subjects who spent more time in the sections closer to the parents (sections 3 and 4 ) versus the two sections farther away (sections 5 and 6 ). The scores for weeks 2,4 , and 6 were all significant at the $2<.01$ level, while week 8 was nonsignificant. During the first three test periods the subjects spent more time close to a parent, while for the last test period, the subjects behaved randomly. These results can be accounted for 
by the fact that the time spent next to the mother declined across time.

Distress vocalizations of the subjects tended to parallel the time spent with the mother. A subject typically vocalized only during the first minute or until it began to explore and find a parent. The mean vocalization rates for the subjects while being tested were $42.8,25.8,12.0$ and 1.0 for weeks $2,4,6$ and 8 respectively. These rates were low, possibly because the subjects were tested in a social situation.

\section{Discussion}

From the results of this experiment, it can be concluded that infant guinea pigs spend more time close to their mother than to their father in a two-choice situation during weeks 2 and 4 of life. Since discrimination as measured by time spent with a stimulus is one of Sluckin's (1970) measures of attachment, it can be inferred that subjects showed attachment to the mother during this time. During week 6, the subjects still spent more time close to the mother, but the frequency of subjects doing so was not significant. During week 8, the subjects appeared to be moving throughout the test box at random.

Most of the experiments with guinea pigs using a two-choice discrimination task have used one familiar 
stimulus and either an empty compartment or a novel stimulus. For example, Nagy and Misanin (1970) paired an unfamiliar guinea pig and an empty chamber while Harper (1970) used a guinea pig model or the mother in one chamber, with the other chamber empty. Carter (1972) paired the test odor against unscented air, and Beauchamp and Hess (1971) used a guinea pig versus a chicken. Since this present experiment used both parents (familiar social stimuli) attraction to the mother could not have been due to attraction to or fear of novel test stimuli. It can be reasonably assumed that the subjects spent more time with the mother during weeks 2 and 4 because of their attachment to her.

The subjects were not able to have any physical contact with the parents except through the wire mesh, and therefore were not able to nurse during the test periods. However, contact through available sensory modalities (auditory, visual, and olfactory) was sufficient to motivate the subjects to maintain proximity to the mother during the first two test periods. These results do not completely agree with those obtained in similar experiments using different species. Latané, Cappell and Joy (1970) found that rats showed little social attraction if they were not able to physically interact with the goal animal. Hull, Langan and Rosselli 
(1973) likewise found that gerbils did not show clear discrimination of social stimuli unless allowed to have physical contact with the choice animals. This species difference might possibly be explained by postulating that guinea pigs rely on non-tactual cues to maintain social contact to a much greater extent than either rats or gerbils.

The first two test periods correspond to the time the infants were being nursed and cared for by their mother, as shown in the Observation of Home Social Behavior. This is also the time period during which the subjects spent the most time engaged in contact behavior. The Chi-square tests confirmed the finding that the subjects spent more time close to the parents during the first three testings but not the last. Also, as a subject matured, it emitted fewer distress vocalizations. These results suggest that the infant guinea pig quickly loses its attachment for a parent as the infant matures. However, another interpretation might be based on the work of Porter, Berryman and Fullerton (1973), who found that infant guinea pigs showed a higher exploration rate when the mother was present although confined. Perhaps the attachment is as strong in later weeks, but the need to actually be in close proximity is not as great. Older guinea pigs might be able to communicate 
attachment through audition, vision, and olfaction, without actually being in close proximity to the attachment stimulus. Perhaps the present testing situation is not large enough to measure proximity properly. If there were more space, it might be found that the subjects would stay within $60 \mathrm{~cm}$. of their mother, which in the present experiment was taken as an indication that attachment had weakened. The present experiment demonstrates that attachment as measured by the two-choice situation can be ambiguous, and that therefore an alternative method of measuring attachment should be sought.

\section{Experiment 1 A}

Reaction of the infant guinea pig to its mother and another familiar adult female in a two-choice situation

In the course of conducting Experiment 1, it happened twice that two litters, each containing one offspring, were born within four hours of each other. It was decided to combine the litters each time, to make two groups, each composed of two infant guinea pigs and two adult mother guinea pigs. These animals were not used in Experiment 1. This situation permitted the experimenter to examine the reaction of the infant guinea pig to its own mother and another adult female with which it had also been reared. The four animals 
in each group were housed in the regular home box, thus permitting social interaction between each infant and two lactating females. Each group contained one male and one female infant.

Testing procedure was identical to that of Experiment, 1, with the exception that the other adult female was used as the stimulus paired with the subject's mother. Testing was carried out on Wednesday of weeks $2,4,6$, and 8 after birth.

\section{Results and Discussion}

The four subjects appeared upset in the test box. They distress vocalized and explored the surroundings. All were active and usually approached both females several times within a test period.

Because the number of subjects was so low, no statistical tests could be applied to the data. If the subjects were wandering about at random, they should have spent an average of 75 seconds in each of the four sections. The data for both sexes was combined. During week 2 , they spent an average of 140.2 seconds in the section closest to their own mother, and 85.7 seconds in the section closest to the other female. During week 4 , the scores were 109.3 and 110.5 seconds for the mother and other female respectively. During week 6 , they responded with 91.3 seconds by the mother and 88.5 
seconds by the other female. During week 8 , the times were 80.8 and 80.3 seconds respectively for the mother and other female.

The results were similar to the results found in Experiment 1, except that the choice of spending a much larger amount of time in the section next to the mother only occurred during week 2. During the other three test periods the amount of time spent in the section closest to each stimulus was so similar that a clear preference could not be seen.

As in Experiment 1, as they became older the subjects spent less time with either stimulus, and more time randomly distributed over the four sections. Throughout the four test periods the average amount of time remained above 75 seconds, but probably not significantly during weeks 6 and 8 .

Distress vocalizations averaged $27.8,27.0,4.0$, and 0.5 for the 5 minute period during weeks $2,4,6$ and 8 respectively. As in Experiment 1, vocalizations rapidly declined with age.

The subject only showed a clear preference for its mother during week 2 of testing. The quick decline in preference behavior after week 2 might be explained by the fact that nursing by both females became less discriminant throughout the four weeks in which nursing 
took place. During the first week of life the infant almost exclusively was found in close proximity to its own mother, often nursing on her. After this time the infants became more active, and it appeared that they nursed to a certain extent on whichever female was available. Throughout the 4 week nursing period, however, the infant spent more time in contact with its own mother and also was observed to nurse more on her. The mothers did not appear to actively discriminate between their own and other infants, but systematic study was not conducted on this variable.

From the results of this experiment it can be concluded that the infant guinea pig spends more time with its own mother than another familiar lactating female during week 2 in a two-choice situation, and after this time appears to choose randomly. Since both females were able to nurse at all times, the choice during week 2 cannot depend upon sex of adult stimulus. In both Experiment 1 and the present one, the difference between time spent with mother and other test stimulus was marked during week 2. During week 4 in Experiment 1, the time spent close to the mother was even greater, while in this experiment no clear choice was shown.

The possibility exists that the mother might have played an active role in directing the infant's behavior. 
When the father was present, he was attacked by the mother if he came into contact with the infant in the mother's presence. In this experiment, however, the mother did not appear to show any agonistic behavior toward the other female.

This experiment demonstrated that the choices given a subject in a two-choice situation may be important when an experimenter is measuring attachment behavior. The opportunities for the subject in the home box may also play an important role, both in terms of the attached stimulus and the strength of attachment.

Experiment 2

Development and habituation of separation distress vocalization

Before using distress vocalization as a measure of attachment, it was necessary to obtain basic information on the expression of distress vocalization in the infant guinea pig under maximum separation from both social and physical surroundings. Experiment 2 was designed to examine the development and habituation of distress vocalization in the infant guinea pig under these conditions. Two separate studies were carried out to obtain this information. One examined the development of distress vocalization when subjects were tested weekly for 12 weeks. The second examined hab- 
ituation effects when 5 week old subjects were tested morning and afternoon for 5 consecutive days.

Method

Subjects

The subjects for the experiment consisted of twenty domestic guinea pigs from seven litters. Ten subjects ( five of each sex) were used in the developmental study and ten different subjects (five of each sex) Nere used in the habituation study. None of these subjects were used in any other experiments.

\section{Procedure}

All testing was conducted in boxes identical to the home box, except fresh bedding was in the test boxes. Each subject was removed from its home box and carried to the test box, which was in the same colony room as the home box. After the subject was placed in the center of the test box, one minute elapsed before recording was started. After 5 minutes of recording, the subject was returned to its home box. The test box was then cleaned and clean bedding was replaced before the next trial. The main dependent variable was frequency of distress vocalizations. Frequency of elimination and freezing were also recorded.

Two separate studies were carried out. In the developmental study, the ten subjects were tested once a 
week, on weeks 1 through 12 after birth. The first test was made when the subjects were 7 days old. Testing was carried out in the mornings. In the habituation study, the subjects were tested twice a day, once in the morning and once in the afternoon, for 5 continuous days during week 5 after birth. Subjects were 35 or 36 days old when testing began. At least 4 hours elapsed between testings of a subject in any one day.

Results

Development

Figure 7 shows the mean total separation distress vocalization rates for the ten subjects for each 5 minute test. The rate in week 1 was 483. This climbed to 555 during week 2 , and then continuously declined until week 12, when seven of the ten subjects did not vocalize. An analysis of variance was run on sex by weeks, with repeated measures on the last variable. The sex variable was nonsignificant $(F=.08, \underline{d f}=1 / 8, n . s$.$) , and hence$ Figure 7 shows the means for both sexes together. The week variable was significant $(F=602.49, \underline{d f}=11 / 88$, $p<.0001)$, confirming the finding of a decline in vocalization across time. An analysis of variance run on only the first 8 weeks was also significant for weeks, $p<$ .0001 .

Habituation 


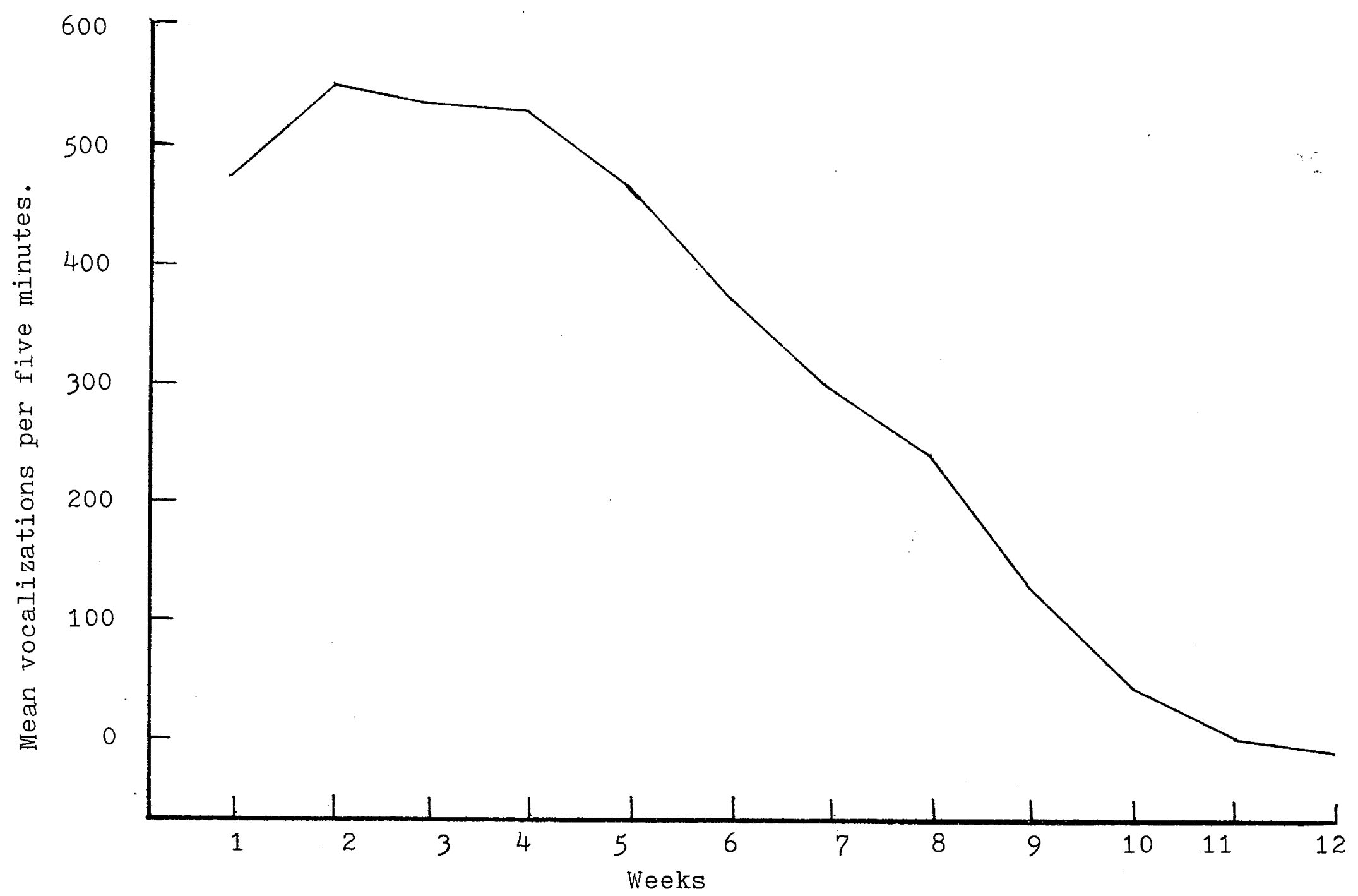

Figure 7. Development of separation distress vocalization. 
Figure 8 shows the mean total separation distress vocalization rates per 5 minutes for both sexes combined. The rate is very stable, ranging from 481 in the morning of day 4 to 432 in the morning of day 5 . There does not appear to be any consistent difference between the morning and afternoon testings. An analysis of variance was run on sex by time by days, with repeated measures on the last two variables. The sex variable was nonsignificant $(F=.08, \underline{d f}=1 / 8$, n.s. $)$, as was the time variable $(F=.04, d f=1 / 8, n . s$.$) and the day variable$ $(F=2.01, \underline{d f}=4 / 32$, n.s. $)$

\section{Discussion}

Between birth and 8 weeks, the separation distress vocalization of infant guinea pigs ranged between 200 and 600. This is a wide range, and except for week 1 to 2, was continuously declining. Therefore care must be taken to realize that this decline is taking place from week to week.

After 8 weeks, the vocalization rate became unreliable and quickly declined until by week 12 it was near zero for most subjects. Separation distress vocalization might only be used as a sensitive measure of attachment during the first 8 weeks of the life of the guinea pig.

As shown in Figure 7 , the vocalization rate began to decline after week 4 . This was the time that the infant guinea pigs became weaned from their mothers. 


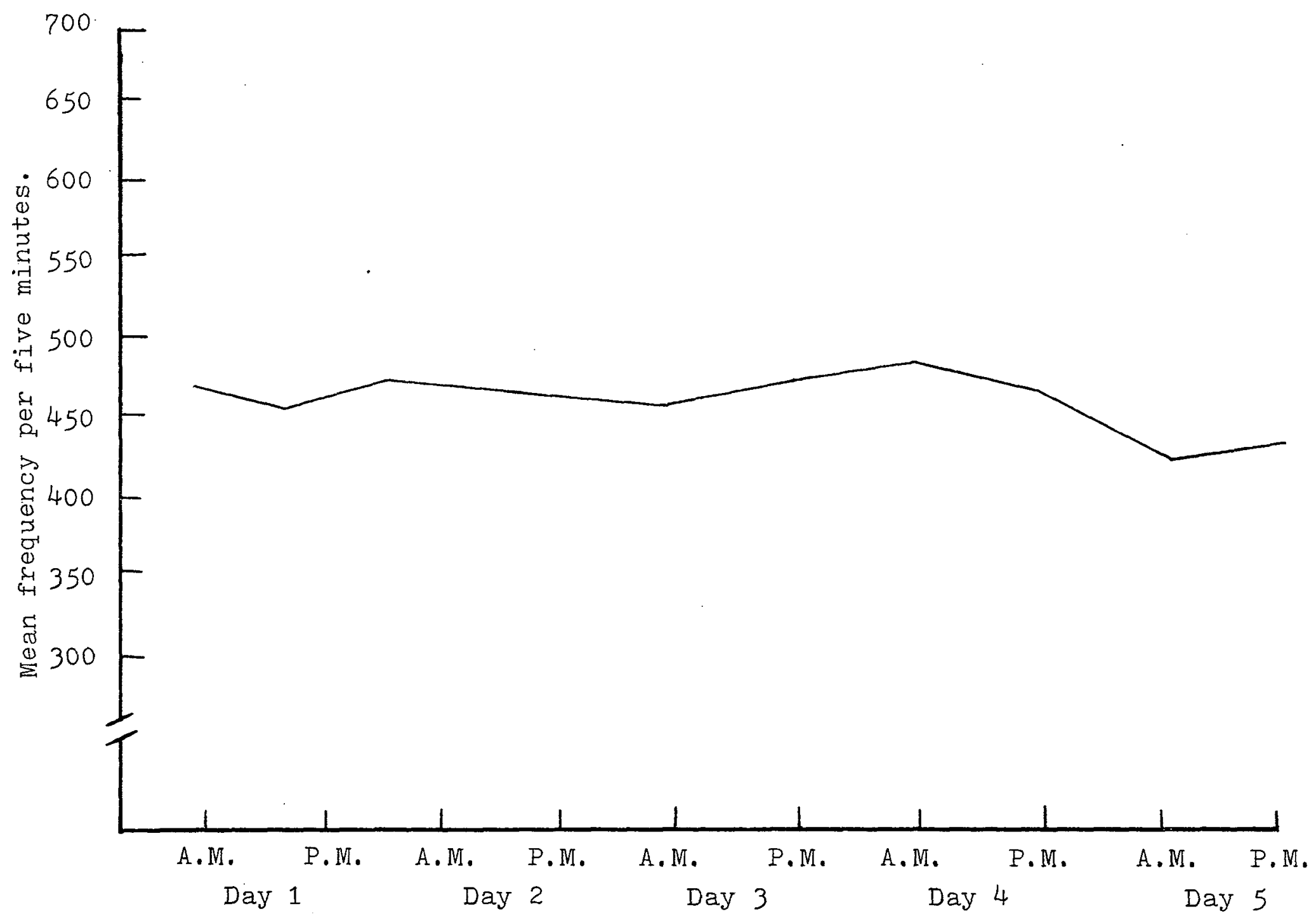

Figure 8. Habituation of separation distress vocalization in five week old guinea pigs. 
This suggests that the strongest attachment to their environment (including both social and physical variables) occurred during the time before the subjects were weaned. Pilot data collected prior to the current study indicated that infant guinea pigs tested in a small container without any physical resemblance to the home pen, without any familiar social companions, and in a room separate from the colony room, had somewhat higher vocalization rates than those in the present experiment. Care was taken in the present experiment to insure that the separation was based on absence of the familiar and not a presence of the strange. Because of the extreme difference in the testing situation of the pilot experiment, it is reasonable to assume that fear of the strange environment might have led to the increase in the vocalization rates. The other experiments in this dissertation all used unfamiliar environments which were identical to the home environment except for being clean. Habituation was only tested during week 5 , and hence it can not be known whether repeated testing might not cause more habituation during another week. Near the eighth week, for example, the decline in vocalization is greater than week 5, thus habituation might take place more readily at this time.

From the habituation results shown in Figure 8 , it 
can be assumed that within the fifth week of life separation distress vocalization in the infant guinea pig does not decline across time and does not differ from morning to afternoon. This is useful information, as it indicates that a subject can be tested twice a day without undue fear of contamination due to habituation. The other experiments in this dissertation did not test a subject more than once a day or four or five times a week. Thus no habituation effects due to repeated exposure should be expected in this study.

\section{Experiment 3}

Reaction of parents to recorded infant distress vocalization

As shown in Experiment 2, the infant guinea pig readily vocalizes when isolated from its familiar surroundings. Experiment 3 investigated the possible role that separation distress vocalization of the infant guinea pig plays in parental attention and behavior. Through comparison of each parent's reaction to being placed in a strange box which was either (a) neutral, or (b) containing a recording of distress vocalization, or (c) a recording of white noise, the importance of infant distress vocalization to the parent was assessed. Method

\section{Subjects}

The eight mothers and eight father of eight litters 
of guinea pigs (ranging from two to six per litter) served as subjects in Experiment 3. These same litters were used as subjects in all of the other major studies except Experiment 2.

Apparatus

The subjects were tested in a clean unfamiliar box which was identical to the home box except it did not contain food or water. To eliminate other noises, the test box was located in a room separate from the colony room. The box was divided into thirds by combining the areas of sections 1 and 2,3 and 4 , and 5 and 6 , as shown in Figure 1. When the condition was a recording, the sound source was a battery-powered cassette tape recorder, placed with its speaker focussed on the center of the outside end of the box.

\section{Procedure}

The three experimental conditions were: (a) no sound (the subject was observed for 5 minutes in the test box as a control); (b) a 5 minute tape recording of a non-related 2 week old infant guinea pig distress vocalizing when isolated; and (c) a 5 minute tape recording of white noise (a fan). In addition, once during each weekly test period one set of parents was selected at random and tested with a live distress vocalizing infant from its own litter in a small cage 
outside one end of the test box to check for any developmental aspects of an infant's distress vocalizing.

Each of the 16 subjects was exposed to each of the three. experimental conditions once on Wednesday of weeks $1,3,5$ and 7 after the birth of a litter. The experimental conditions were presented in a random order, with at least one hour between tests. A subject which was to be tested with vocalizations from a live infant was exposed to the infant's vocalizations after the three experimental conditions had been given on that day.

For each test, the subject was removed from its home box and carried into the testing room. It was then placed in the center of the box facing midway between the ends. Data were recorded for 5 minutes.

The time spent in each third of the test box was recorded in seconds. The main dependent variable was the number of seconds spent in the third of the box closest to the sound source ( 300 maximum). Behavior exhibited by the subject was recorded on the behavior check list.

\section{Results}

In a typical test session, the subject slowly investigated the entire box, weaving about until it covered all areas. Males tended to take more time for this systematic investigation before stopping and sitting 
still. Many subjects were active throughout most of the 5 minute period, slowly wandering back and forth in the box.

The amount of time spent in the sound source end of the box under the three experimental conditions is shown in Figure 9. If a subject were responding randomly, it should spend approximately 33 per cent (100 seconds) in each of the thirds of the test box under each experimental condition. An analysis of variance with repeated measures on the last two factors was run on sex by sound by week for the amount of time the subject spent in the area closest to the sound source. The sex variable was slightly nonsignificant, $F=4.20, \underline{d f}=1 / 14$, $\mathrm{p}<.10$ ), indicating that overall the mothers and the fathers responded fairly similarly to the experimental conditions. The week variable was significant $(F=5.46$, $\underline{d f}=3 / 42, p<.005)$ and the sound source variable was highly significant $(F=10.19, \underline{d f}=2 / 28, \underline{p}<.001)$.

These results suggest that both sexes responded differentially to the conditions and that there was a developmental effect. However, as shown in Figure 9, the only strongly deviant response from randommess appears to be the behavior of the mothers in the condition of the recorded distress vocalization during week 1 after the litter was born, when the mean time 


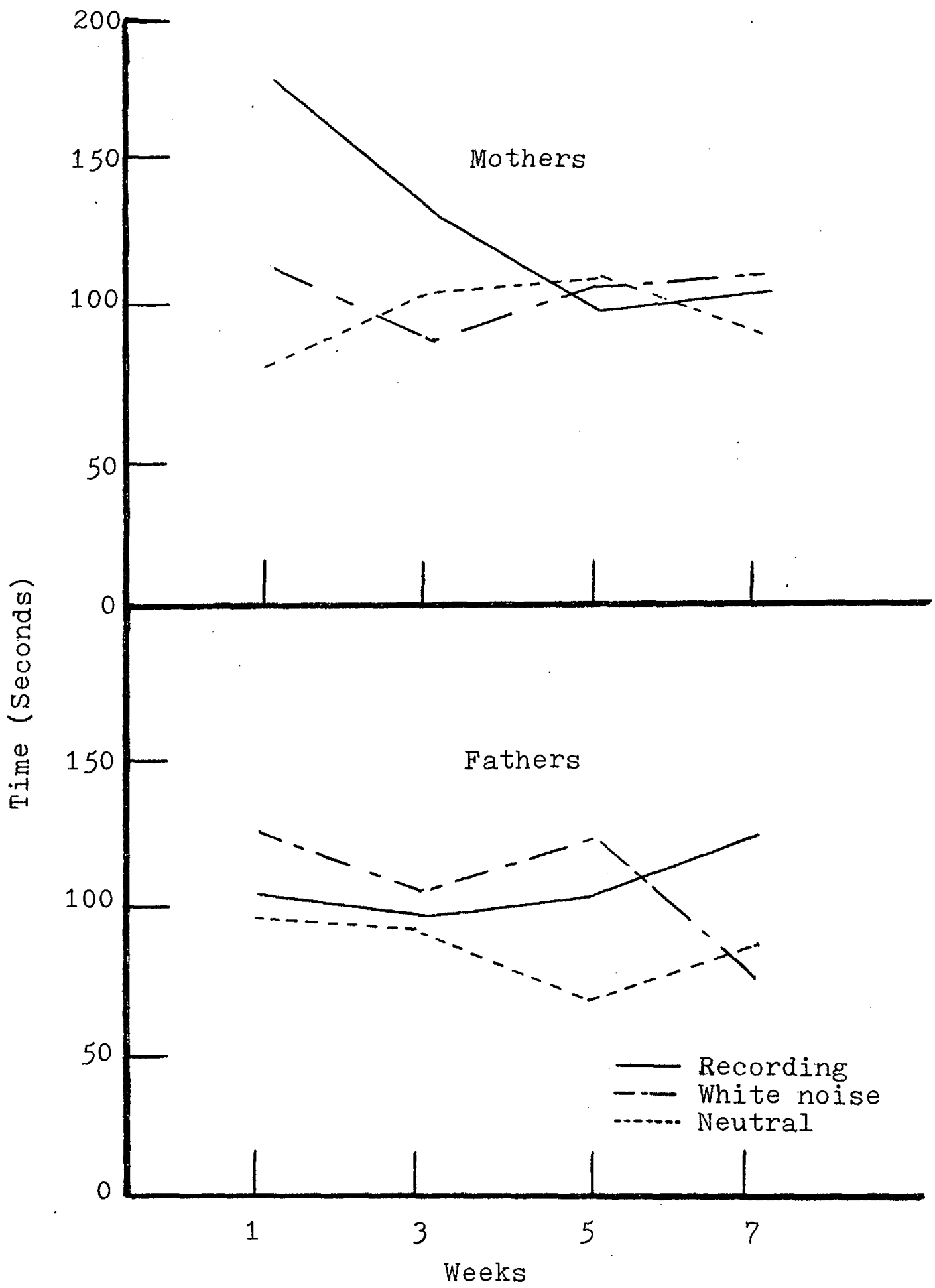

Figure 9. Mean amount of time parents spent in end with sound source in a 5 minute period. 
spent in the section closest to the sound source was 179.3 seconds. The mean score for the mothers in the vocalization condition during wék 3 was 130.0 seconds, which was elevated, but not as greatly as in week 1. During weeks 5 and 7 the mothers responded randomly when in the distress vocalization condition. The scores of the fathers indicated random movement, with the first three test periods being about 100 seconds, and the score for week 7 being 123.4 seconds near the sound source. Both the mothers and the fathers appeared to respond randomly to the neutral and white noise sound conditions with scores of approximately 100 seconds. These findings can be explained by the finding of a highly significant sex by sound by week interaction, $F=6.34, \underline{d f}=6 / 84, \underline{p}$ $<.0001$. The significance of weeks and sound source can be attributed to the extremely high score for the mothers during week 1 in the condition containing the recording of distress vocalizations. None of the other interactions were significant, again emphasizing the deviant score for the mothers during the first week.

A separate analysis of variance was run for the scores of each week on sex by noise. The only significant findings were in week 1 , when sex was significant $(F=7.28$, $\underline{\mathrm{df}}=1 / 14, \underline{\mathrm{p}}<.05$, sound source was highly significant $(F=20.46, \underline{d f}=2 / 28, \underline{p}<.001)$, and the sex by sound 
source interaction was also highly significant $(F=20.30$, $\underline{d f}=2 / 28, \underline{p}<.001)$. This confirms that the behavior of both parents was random except during week 1 when the mothers reacted to the recordings of infant distress vocalizations.

The check tests using a live distress vocalizing offspring generally agreed with the results obtained with the tape recording. The mother responded strongly only during week 1 and the father did not respond strongly at any time. This suggests that the decline in maternal responsiveness is not due to a change in the offspring's vocalization.

\section{Discussion}

As shown in the Observation of Home Social Behavior, the infant guinea pig is weaned by its mother between 3 and 4 weeks after birth. This fact might account for the lower rate of maternal response after week 1 . Since the infant guinea pig of 3 weeks or older does not require maternal care, it would be most useful for the mother to be greatly concerned for her offspring only during the earliest period of time after birth. The parents were not tested during week 2 , and hence the development can not be accurately shown. The week 2 value would probably be somewhere midway between the values for weeks 1 and 3. The infant guinea pig is 
independent of its mother during weeks 5 and 7 of testing, agreeing with the finding that maternal responsiveness is random during these last two test periods.

There are several possible reasons for the decline in maternal behavior. The offspring may change by engaging in behaviors which weaken maternal behavior (slich as higher activity or stronger resistance) or the offspring may change by not engaging in behaviors which elicit maternal responsiveness (such as no longer crying for attention). The infant may also change physiologically so as to cause the mother to lose interest or to become aversive. The mother may also change physiologically, which may result in less maternal behavior. Another possibility is that the mother might have learned that she was unable to contact the vocalizing infant. Since maternal reaction was similar to the recorded distress vocalizations of a non-related 2 week old infant and the distress vocalizations of the mother's aging offspring, it was assumed that changes within the mother were important in the decline in maternal responsiveness to distress vocalization after week 1 .

The finding that the fathers did not strongly respond to tape recorded distress vocalizations of infant guinea pigs at any time corresponds to the observation that young guinea pigs rarely interact with their father 
until after 6 weeks of age, when the father begins to be able to investigate his offspring without the mother attacking him. The trend toward an increase in time spent by the father in the sound source end of the box when the condition was a recording of distress vocalization during week 7 , although nonsignificant, agrees with the observation that the father does interact with the offspring in the home box at this time.

The current results may help explain the conflicting reports which have been made concerning guinea pig maternal reaction to distressed infants. King (1956) reported mothers would sometimes go to their young, while Kunkel and Kunkel (1964) stated that mothers always went to vocalizing young, and Rood (1972) noted mothers often completely ignored their young. These authors did not always specify the exact age of the infants when the observations were made. From the results obtained in the present experiment, during the first couple of weeks it would be predicted that mothers would go to their offspring, and that during the next couple of weeks the responses would be less reliable. After this, the mothers might completely ignore the offspring. The current results lead to the conclusion that paternal reaction to the distress vocalizing infant guinea pig is absent, and that maternal reaction is 
chiefly limited to the first few weeks of life.

\section{Experiment 4}

Attachment in infant guinea pigs as measured by separation distress vocalization

It has been shown in the observational data that infant guinea pigs spend much time following and attempting to maintain close proximity to each other and their mothers. Experiment 1 showed that during weeks 2 and 4 infants spend more time with their mothers when in a two-choice situation. Distress vocalization is produced in infants when they are isolated from their familiar surroundings. Experiment 4 was designed to use separation distress vocalization to measure attachment to social and physical environments in the infant guinea pig.

Method

$\underline{\text { Subjects }}$

Thirty-four infant guinea pigs, 17 of each sex, served as subjects in this experiment. They were tested from birth to 8 weeks of age. Twenty-four of the subjects had been used in previous experiments in this dissertation; ten additional subjects were used exclusively in the present study. Apparatus

The subjects were tested in their home box, with 
no physical changes, and in a clean unfamiliar box, identical to the home box except that it contained fresh bedding. All testing was done in the colony room. The unfamiliar box was cleaned before each test.

\section{Procedure}

Two main variables were manipulated; (a) presence or absence of mother (social environment); and (b) presence or absence of home box (physical environment). Thus there were four experimental test conditions: (a) mother and home box; (b) mother and unfamiliar box; (c) alone in home box; and (d) alone in unfamiliar box. Each subject was tested in one of the four experimental test conditions each day: Monday, Tuesday, Thursday and Friday of weeks 1 through 8 after birth. Each subject was given only one test per day. The order of test conditions was determined prior to the beginning of the experiment for each subject, and the same order was followed each week for each subject.

The subject being tested along with its parents and littermates was removed from its home box and placed in a holding box; $30 \times 50 \times 30 \mathrm{~cm}$. Then the subject was placed into the testing situation, and its behavior was recorded for 5 minutes. The main dependent measure was the frequency of distress vocalizations emitted by the subject. If the mother was designated to be present, 
the infant was placed in the box $10 \mathrm{~cm}$. from the mother and facing her. The subject (and its mother) were always in the center of the box when testing began.

Since attachment may be to either physical or social environment, it was predicted that the fewest vocalizations would occur in condition (a), which had both the mother and the home box. The highest rate should have occurred in condition (d), when neither type of familiar surrounding was present. If condition ( $b$ ) was higher than condition ( $c$ ), then physical environment was more important, whereas if condition (c) was higher than condition (b), social environment was of greater importance in the infant guinea pig's attachment. Because maternal attention was low, it was predicted that the most important variable in attachment formation would be the physical environment.

\section{Results}

In a typical 5 minute test session, the behavior of the subject was determined by the presence or absence of the mother. When she was present, the subject approached her and maintained contact for most of the test session. This occurred throughout the 8 weeks of testing. Most vocalizations occurred within the first. 2 minutes of testing. However, when the mother was absent the subject wandered throughout the box, showing explor- 
atory behavior. Often this was the time of the most vocalizations. When the subject froze, it often became silent. This samesbehavior pattern occurred whether the subject was tested in the home box or the unfamiliar box. Figure 10 shows the mean vocalization rates for 5 minutes under the four experimental conditions (motherhome, mother-unfamiliar, alone-home, alone-unfamiliar). When the mother was present the vocalization rates were low throughout the 8 weeks of testing. When the mother was absent, vocalization rates were high, as confirmed by the finding of overall significance for the presence or absence of the mother (social environment) ( $F=693.83$, $\underline{\mathrm{df}}=1 / 32, \underline{\mathrm{p}}<.001)$. The overall vocalization means were 145 and 158 for 5 minutes for females and males respectively, which were not significantly different $(F=$ 1.16, $\underline{d f}=1 / 32)$. Therefore, in Figure 10 the scores for both sexes were combined. The week variable was found to be significant, $(F=31.70, \underline{d f}=7 / 224, p<.001)$, confirming the finding that the vocalization rate declined across the 8 weeks of testing as would be expected from the results of Experiment 2. The presence or absence of the home box (location or physical environment) was also found to be significant $(F=110.69, \underline{d f}=1 / 32, p<.0001)$, indicating that the place of testing was important. Several interactions were significant, and are 


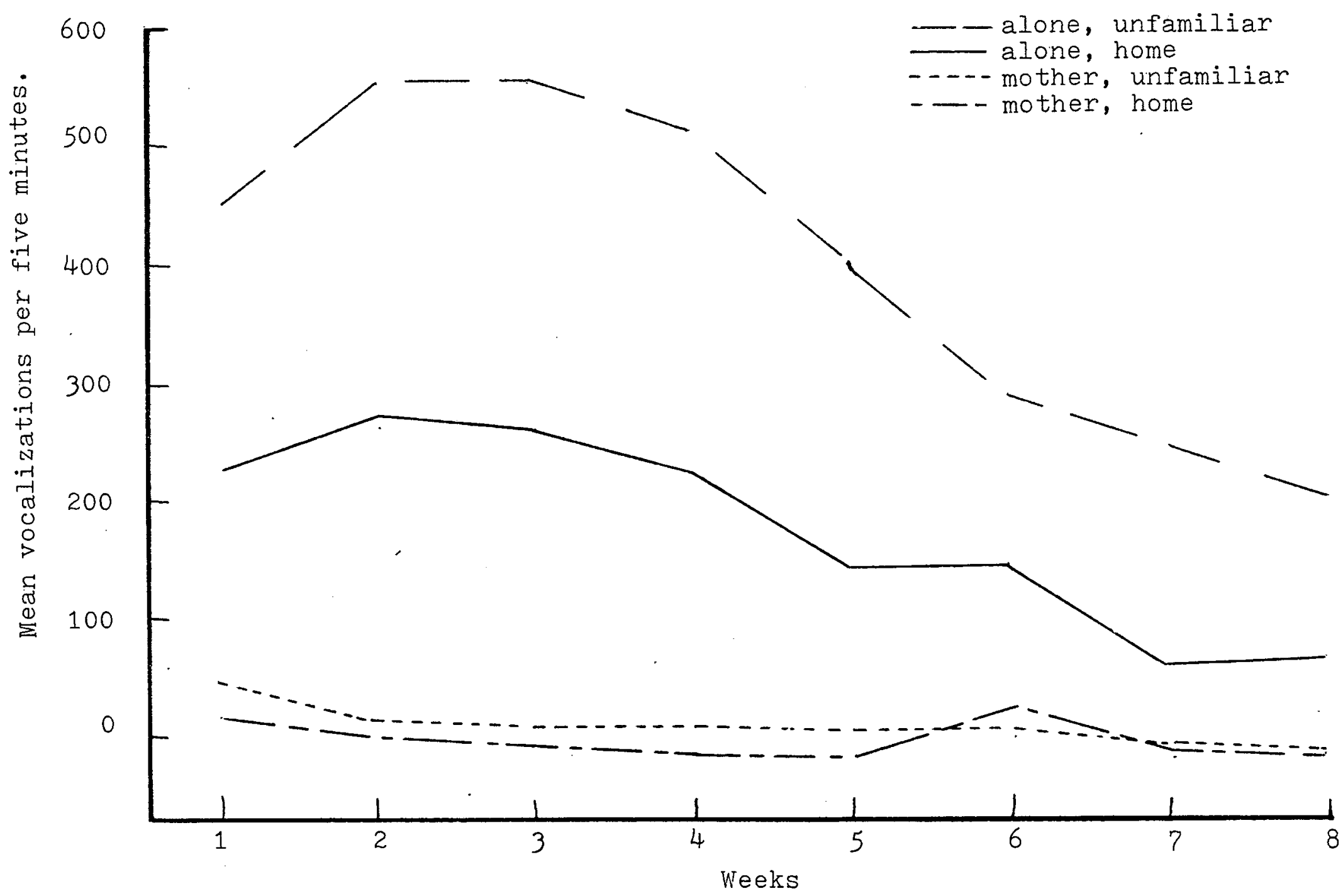

- Figure 10. Attachment to social and physical environment as measured by separation distress vocalization in infant guinea pigs. 
helpful in explaining the results. When the mother was absent, the vocalization rate in the alone-home condition was moderate, while in the alone-unfamiliar condition it was extremely high. This finding is confirmed by the significant social by physical environment interaction $(\mathrm{F}=158.14, \mathrm{df}=1 / 32 . \mathrm{p}<.0001)$. The alone-unfamiliar vocalization rate was around 450 during week 1 , rose to near 550 during week 3 and then slowly declined until it was near 250 during week 8. This pattern is confirmed by the finding of a week by social environment interaction $(\mathrm{F}=29.24, \underline{\mathrm{df}}=7 / 224, \mathrm{p}<.0001)$. Likewise in the alone conditions, both the home and unfamiliar conditions decline across weeks, as indicated by the finding of a significant week by physical environment interaction $(\mathrm{F}=6.71, \underline{\mathrm{df}}=7 / 224, \mathrm{p}<.0001)$. As shown in Figure 10, when the mother is present, vocalization rates are low, and when she is absent, the location of testing is important. This is confirmed by the finding of the social by physical environment interaction $(F=158.14, \underline{d f}=1 / 32$, $\mathrm{p}<.0001)$. Finally, the scores from both the social and physical environmental variables are all known. This is confirmed by the finding of a significant week.by social by physical environment interaction $(F=4.69, \mathrm{df}=7 / 224$, $\mathrm{p}<.0005)$.

Separate analyses were carried out on the sex, social 
and physical environment variables for each week. The sex variable was significant $(.05)$ only during week 1 , when the females vocalized slightly higher than the males. The social variable was significant at the $\underline{p}<.0001$ level for every week. The physical environment variable was significant at the $\underline{p}<.0001$ level for all weeks except week 6 when it was significant at the $p<.05$ level and week 8 when it was significant at the $p<.0005$ level. The social by physical environment interaction was significant at the $p<.0001$ level for the first 5 weeks and at the $\mathrm{p}<.0005$ level for the last 3 weeks. These analyses indicate that sex of the animal is not important, but that social and physical environment are both extremely important variables when examining separation-induced distress vocalization in the infant guinea pig.

\section{Discussion}

The results of this experiment indicate that the social variable was of the greatest importance in terms of regulating separation distress vocalization. When the mother was present, the vocalization rate was extremely low throughout the experiment, whereas when the mother was absent, the vocalization rate was moderately or extremely high, depending on the physical environment. 
The highest rate of vocalization occurred during weeks 3 and 4 in the alone-unfamiliar condition, which corresponds to the time the mothers weaned their offspring. After this time, the infants were still usually allowed to maintain contact with the mother, but if the infant attempted to nurse, the mother would often attack and bite it.

The subjects very rarely ate or drank, either when in the home or unfamiliar box. When the mother was present the subject spent most of its time approaching her, following her, or maintaining contact with her. Occassionally when the mother would eat, the subject also ate. When it was alone, the subject appeared extremely upset, and spent most of its time vocalizing.

It is interesting that sex of the subject was not a significant variable. However, none of the subjects were sexually mature during the experiment. The males did begin to show courting gestures during the last 2 weeks, at which time the fathers also began to interact more with the offspring. The finding that the females vocalized significartly higher than males only during week 1 might be explained by the finding by Read (1912) that females are usually larger and stronger at birth, but males catch up within the first week.

The finding that the alone-unfamiliar condition 
elicited a much higher vocalization rate than the alonehome one demonstrated that the infant guinea pig forms some attachment to its home physical environment although not as much as to its social environment. The home and unfamiliar boxes were very similar to one another, the main difference being that the unfamiliar box had clean bedding for each test. This small change was enough to produce much higher vocalization rates. Olfactory cues might be important in guinea pig social and physical environment attachment, since both the bedding and the mother would contain home odors. Future research might investigate this possibility.

\section{Experiment 4 A}

Social attachment variables and separation distress vocalization

The results of Experiment 4 clearly show that the infant guinea pig is attached to its mother. When separated from her, the infant distress vocalized, whether at home (by i.tself) or isolated in an unfamiliar environment. It was not shown, however, whether the presence of the mother was required or whether any guinea pig could alleviate the separation distress.

The results of Harper (1970), Nagy and Misinan (1970), and Beauchamp and Hess (1971) might suggest that the guinea pig forms a species attachment rather than attach- 
ment to specific individuals. Harlow (1962) is the only observer to contradict this idea. He watched his daughter's pets and concluded that guinea pigs form individual sexual attachments which are relatively permanent. The concept of a general attachment might help explain some of the conflicting mother-infant relationship results. Experiment $4 \mathrm{~A}$ was designed to examine several possible sources of social attachment in the infant guinea pig: mother, father, sibling, and unfamiliar adult female.

Method

This experiment used six infant guinea pigs from two litters, five males and one female. They were tested during the first 4 weeks of life. None of the subjects served in any other experiment.

The subjects were always tested in a clean, unfamiliar box that was identical to the home box except the test box contained fresh bedding. Testing was conducted Monday through Friday, usually in the morning.

Each subject was tested in five conditions each week: (a) isolated, (b) with its mother, (c) with its father, (d) with an unfamiliar adult female, and (e) with a sibling. The order of the first four conditions was determined by a table of random numbers for each subject. They were given Monday through Thursday of each week. The fifth condition was always given on Friday. 
The subject was tested for 5 minutes. The main dependent variable was the frequency of distress vocalizations emitted by the subject. For the sibling condition, the total vocalization for each pair was divided by two for an individual score.

\section{Results and Discussion}

Figure 11 shows the distress vocalization scores when the subjects were tested under the five experimental treatments. Every social stimulus reduced the vocalization rate from levels when the subject was isolated. The mother was the most effective stimulus in reducing vocalizations, followed by the father, a sibling, and an unfamiliar adult female respectively. The scores for the familiar social stimuli were all similar, whereas the score for the unfamiliar social stimulus was higher. No statistical analyses were carried out on the data because of the small number of subjects involved.

The vocalization curve for the isolated condition is similar to the curves found in Experiment 2 and in Experiment 4 under identical conditions. The main difference is that the curve in this experiment did not increase between weeks 1 and 2 as the others did. This might be explained because of the small number of subjects and the high variance in this experiment. 


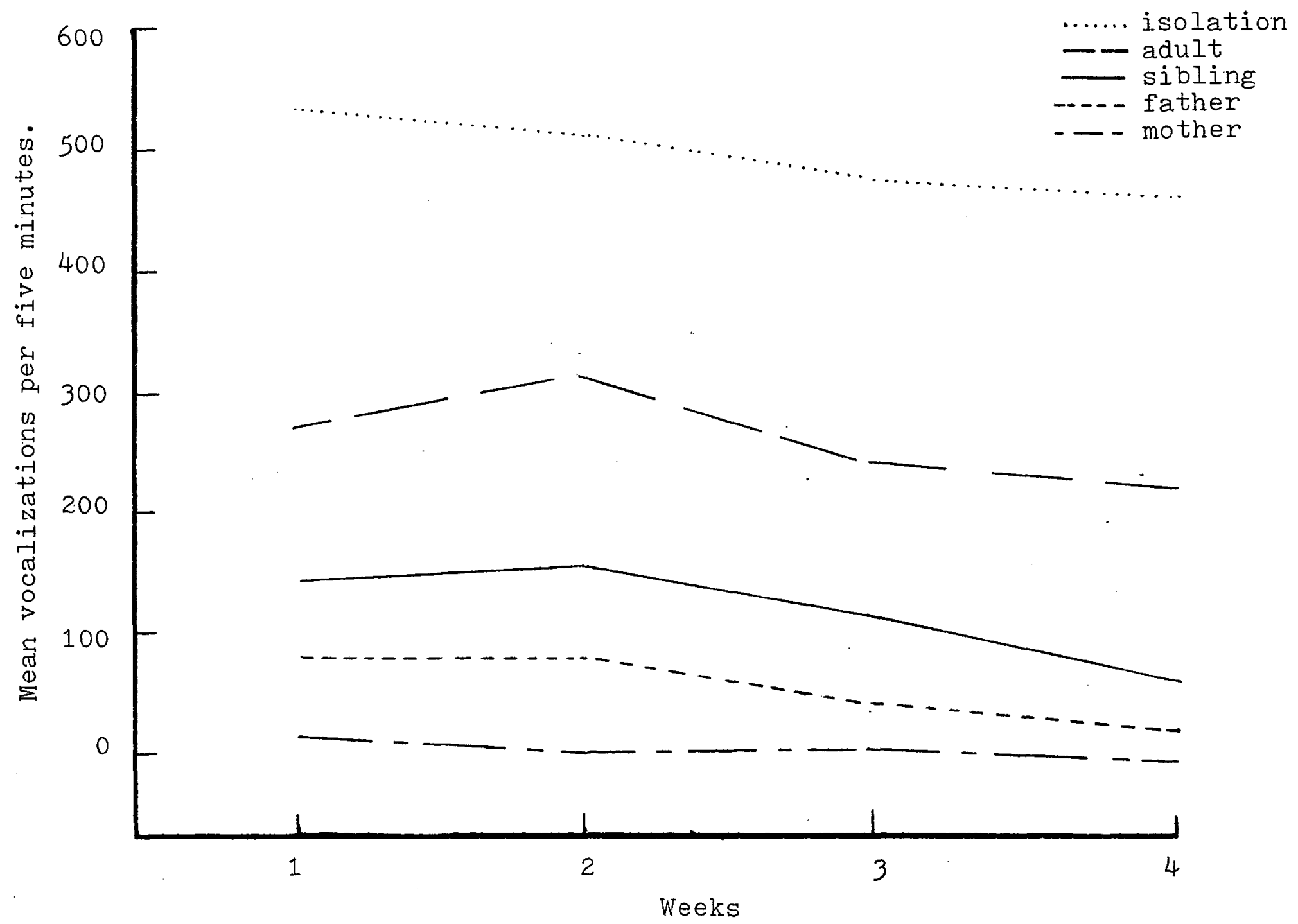

Figure 11. Attachment to social stimuli as measured by separation distress vocalization in infant guinea pigs. 
It was expected that the mother would be the most effective stimulus, but it was somewhat surprising to find that the father might be more effective than a sibling, since little interaction took place between a father and his offspring during the time this experiment was conducted. In the Observation of Home Social Behavior, it was found that the subjects followed, approached, and maintained contact with one another and the mother. Hence it might be assumed that these behaviors are not necessary for attachment to take place. It was sufficient for the infant to see, smell and hear the father in order to form an attachment toward him.

The finding that the father is effective in repressing distress vocalization in his offspring does not completely agree with Experiment 1, in which the offspring did not choose to spend more time with its father than its mother. Experiment 3 demonstrated that the father did not respond to a recording of infant distress vocalization. Perhaps the father was similar enough to the mother (in size, odor, and behavior) for the subjects to be comforted when in an unfamiliar environment.

The results of this experiment lead to the conclusion that infant guinea pigs can discriminate between familiar and unfamiliar social stimuli as measured by distress vocalization. The attachment to the subject's familiar 
social stimuli should be further investigated to find the cues the infant guinea pig uses to form social attachments.

\section{General discussion}

Attachment in infant guinea pigs was measured in several different ways in this dissertation. Separationinduced distress vocalization was examined in terms of its development over time, its effect on the infant's parents, and its usefulness as a measurement of infant attachment. Following is an evaluation of separation distress as a measure of attachment in the infant guinea pig.

Experiment 1 employed a widely accepted method of attachment measurement, the two-choice situation. The results of Experiment 1 showed that infant guinea pigs spent more time in close proximity to the mother than to the father during weeks 2 and 4 after birth. During weeks 6 and 8 the time was equally divided. The conclusion from the data might be that strong attachment to the mother was only present during weeks 2 and 4 . However, Experiment 4 results provided a somewhat different view of attachment during the latter part of the period.

Experiment 4 results showed high vocalization. 
rates when the subject was separated from its mother. The vocalization rate was significantly higher when the mother was absent during the entire 8 weeks of testing. Thus, one might conclude that strong attachment to the mother extended for the first 8 weeks of life rather than weeks 2 and 4 only.

It had been predicted that the results obtained using separation distress would agree with the results obtained using a two-choice situation. A Spearman Rank Correlation Coefficient was thus run to determine whether the subjects who showed strong preference for the mother also showed great distress when the mother was absent. The 24 subjects which were used in both Experiments 1 and 4 were employed in the comparison. For weeks 2 and 4 the correlations were .73 and .61 respectively, which were both significant at $\mathrm{p}<.01$. Week 6 scores were correlated .42 , which was significant at the $\mathrm{p}<.05$ level. Week 8 scores were correlated .23, which was not significant. The two measures of attachment agree during all but the last test period, although the strength of agreement steadily decreases across time. The number of subjects showing zero vocalizations increased near the eighth week, thus affecting the correlation. It is argued that the two-choice situation 
does not adequately test attachment in the older infant guinea pig, and that this accounted for the lack of strong agreement between the two methods.

The two-choice situation was based on the assumption that time spent near one stimulus was indicative of strength of attachment. In Experiment 1, the subjects were tested in an area of $60 \times 60 \mathrm{~cm}$. As the infant guinea pig became older, it may not be necessary for close proximity to occur. Perhaps the test box was not large enough to determine how far the subject would wander away from its mother. In the test situation, sight, smell and hearing might be sufficient for the subject to feel secure even in the farthest corner of the box. These questions on the interpretation of data do not occur when separation-induced distress is used as the dependent measure.

Experiment 4 A found that separation distress of infant guinea pigs can be reduced by the presence of the father. Thus in Experiment 1, the father might have acted as a comforting stimulus, suggesting another explanation of the lack of distress in the subjects.

In Experiment 4, the subjects greatly vocalized when the mother was absent and did not greatly vocalize when she was present. There can be no other interpretation than that the subjects were distressed in her absence 
and that their distress was alleviated by her presence. Thus it can be concluded that separation distress is an effective method of attachment measurement.

The finding that, as measured by distress vocalization, the guinea pig was more disturbed when its familiar social environment was absent that when its familiar physical environment was absent agreed with studies using other species. The social stimulus (mother) reduced distress vocalizations even in the unfamiliar environment. This result was also found in kittens (Rheingold and Eckerman, 1971), rhesus monkeys (Jensen and Tolman, 1962), humans (Rheingold, 1969), and puppies (Scott and Bronson, 1964; Pettijohn, Wong, Ebert and Scott, 1974). The guinea pigs vocalized less in the home environment than in the unfamiliar environment. This finding was similar to that in puppies (Elliot and Scott, 1961), and a study with kittens (Rosenblatt, Turkewitz and Schneirla, 1969). Rheingold and Eckerman (1971) however, did not find that home environment reduced distress vocalizations in kittens. These comparisons showed that the guinea pig was similar to many other young mammals in its reaction to separation from familiar surroundings by distress vocalizations. The comparisons also demonstrated that vocalizations were 
usually greatly reduced when a familiar social stimulus was present, while a familiar non-social stimulus was not as effective.

Although the present dissertation was the first systematic attempt at investigating attachment by the use of separation distress, many studies have looked at attachment in the guinea pig. In general, the results in the present dissertation support and extend the results of other researchers. Some of the previous work has concentrated on infants under 4 weeks old, and hence it would be difficult to speculate on behavior during the second month of life. However, following is a comparison of the present results with those found by other researchers.

The observational data in the present dissertation showed farily high rates of following, approaching and contact in infants even during the first few weeks. This agrees with Gaston, Stout and Tom (1969) who found that infants followed an imprinted stimulus within a few days of birth. Likewise, Harper (1970) found infants a week old were reinforced for maze running behavior by presentation of an imprinted stimulus.

Experiment 1 found that infants spent more time close to the mother during weeks 2 and 4 after birth 
when paired with the father, and only during week 2 when paired with another female they were housed with. This disagrees somewhat with Porter, Fullerton and Berryman (1973) who found that infants did not discriminate between the mother and another female they were housed with. However, Fullerton, Berryman and Porter (1974) found infants were more often observed to nurse and remain close to their biological. mother than another female they were also housed with. They also found that if the infants were isolated for a short time, their behavior became indiscriminant. The technique varied and this might account for the discrepancy. The present experiment does support the general notion that infant choice behavior is not strong under these conditions.

Experiment 3 found that mothers respond to a recording of infant vocalizations only during the first week after birth, and fathers never strongly respond to a recording. Kunkel and Kunkel (1964) also reported an absence of paternal care of the young. Rood (1972) found maternal behavior to be strongest in the very early life of the offspring. Kunkel and Kunkel (1964) reported that some mothers began weaning at about 3 weeks. Again, the results of the present experiment generally agree with existing information on guinea pig 
parental responsiveness toward infants.

Experiment 4 found that by using separation distress, social attachment is of more importance than the physical environment to the infant guinea pig. This agrees in general to the idea of early social imprinting which rapidly declines. No one has previously used separation distress in the guinea pig, however several studies have reported that infant guinea pigs vocalize when separated from home and family (Tobach and Gold, 1966; King, 1956; Sluckin, 1968; Kunkel and Kunkel, 1964; Rood, 1972; Berryman, 1970). The present experiment has extended and systematically studied some of the causes of separation distress and its relation to attachment.

The finding that separation induced distress vocalization can be used to measure attachment in the infant guinea pig gives the researcher a useful subject animal. Although the evolution of the domestic guinea pig is not certain, and thus attachment cannot be accurately judged as to historical importance, the current attachment behavior of the guinea pig has been shown to be similar to other young mammals when measured by separation distress. Any number of variables could be tested with this method and the present dissertation only explored some of the most obvious ones. More work is needed in the area of description of early mother-offspring 
attachment. Future research can use separation-induced distress vocalization to further investigate the motherinfant bond in the home environment. 
References

Ainsworth, M.D.S. The development of infant-mother attachment. In B.M. Caldwell \& H.N. Ricciuti, (Eds.), Review of Child Development Research, Vol. 3. Chicago: Univ. of Chicago Press, 1973.

Allen, J. The associative process of the guinea pig. Journal of Comparative Neurology \& Psychology, 1904 , 14, 293-359.

Beauchamp, G.K. \& Hess, E.H. The effects of cross-species rearing on the social and sexual preferences of guinea pigs. ‥ Tierpsycho1., 1971, 28, 69-76. Bermant, G. Intensity and rate of distress calling in chicks as a function of social contact. Animal Behavior, 1963, 6 (4), 514-517.

Berryman, J. Guinea pig vocalizations. Guinea Pig News Letter, 1970, October, 9-18.

Cairns, R. Attachment behavior of mammals. Psychological Review, 1966, 23, 409-426.

Carter, C.S. Effects of olfactory experience on the behavior of the guinea pig (Cavia porcellus). Animal Behavior, 1970, 18, 238-244.

Carter, C.S. \& Marr, J.N. Olfactory imprinting and age variables in the guinea pig, Cavia porcellus. Animal Behavior, 1970, 18, 238-244.

Elliot, 0. \& Scott, J.P. The development of emotional distress reactions to separation in puppies. Journal of Genetic Psychology, 1961, 29, 3-22. 
Fredericson, E. "Perceptual homeostasis and distress vocalization in puppies," Journal of Personality, $1952,20,472-477$.

Fullerton, C., Berryman, J. \& Porter, R. On the nature of mother-infant interactions in the guinea pig (Cavia porcellus). Behaviour, 1974, 48, 145-156. Gaston, M.G., Stout, G.R. \& Tom, R. Imprinting in guinea pigs. Psychonomic Science, 1969, 16, 53-54. Harlow, H.F. Love in infant monkeys. Scientific American, 1959, $200(\underline{6}), 68-74$.

Harlow, H.F. The heterosexual affectional system in monkeys. American Psychologist, 1962, 17, 1-9. Harper, I.V. The effects of isolation from birth on the social behaviour of guinea pigs in adulthood. Animal Behaviour, $1968,16,58-64$.

Harper, I.V. Role of contact and sound in eliciting filial responses and development of social attachment in domestic guinea pigs. Journal of Comparative \& Physiological Psychology, 1970, 23 (3), 427-435. Hess, E.H. Imprinting. Science, 1959, 130, 133-141. Hoffman, H.S. The control of distress vocalization by an imprinted stimulus. Behaviour, 1968, 30, 175-191. Hoffman, H.S., Barrett, J., Ratner, A., \& Singer, D. Conditioned suppression of distress calls in imprinted ducklings. Journal of Comparative \& Physiological Psychology, 1972, 80 (30), 357-364. 
Hull, E., Langan, C., \& Rosselli, I. Population density and social, territorial and physiological measures in the gerbil (Meriones onguiculatus), Journal of Comparative \& Physiological Psychology, 1973, 84, $414-422$.

Jensen, G.D. \& Tolman, C.W. Mother-infant relationship in the monkey, Macaca nemestrina: The effect of brief separation and mother-infant specificity. Journal of Comparative \& Physiological Psychology, $1962,55,131-136$.

King, J.A. Social relations of the domestic guinea pig living under semi-natural conditions. Ecology, 1956, 37, $221-228$.

King, J.A. Maternal behavior in Peromyscus. In H.I. Rheingold (Ed.), Maternal behavior in mammals, New York: John Wiley, 1963.

Kunkel, P. \& Kunkel, I. Beitrage Zur Ethologiedes Hausmeer-Schweinchens Cavia aperea f. porcellus. $\underline{\text { f. }}$ Tierpsychol., 1964, 21, 602-641. Translated by W. Jacobs, Univ, of Chicago, Unpublished. Latané, B., Cappell, H. \& Joy, V. Social deprivation, housing density and gregariousness in rats. Journal of Comparative \& Physiological Psychology, 1970, 20, . $221-227$.

Nagy, Z.M. \& Misanin, J.R. Social preference in the guinea pig as a function of social rearing conditions and age at separation from the mother. Psychonomic Science, $1970,19(5), 309-311$. 
Pettijohn, T.F., Wong, T.W., Ebert, P.D., \& Scott, J.P. Alleviation of separation distress in three breeds of young dogs. Manuscript in preparation.

Porter, R., Berryman, J. \& Fulierton, C. Exploration and attachment behavior in infant guinea pigs. Behaviour, 1973, 45, 312-322.

Porter, R., Fullerton, C., \& Berryman, J. Guinea pig maternal-young attachment behavior. $Z$. Tierpsychol., $1973,22,489-495$.

Read, J.M. Observations on the suckling period in the guinea pig. Univ. of Calif. Pub. in Zool., (19111913), 1912, IX, 341-351.

Rheingold, H.L. The effect of a strange environment on the behavior of infants. In B.M. Foss (Ed.), Determinants of Infant Behavior: IV. Iondon: Methuen, 1969, 137-166.

Rheingold, H.I. \& Eckerman, C.O. Familiar social and nonsocial stimuli and the kitten's response to a strange environment. Developmental Psychobiology. 1971, 4 , $71-89$.

Rood, J.P. Ecological and behavioural comparisons of three genera of Argentine cavies. Animal Behavior Monographs, 1972,5 (1).

Rosenblatt, J.S. \& Schneirla, T.C. The behavior of cats. In E.S.E. Hafex (Ed.), The Behavior of Domestic Animals. Baltimore: Wilkins \& Wilkins, 1962,453-388. 
Rosenblatt, J.S., Turkewitz, G. \& Schneirla, T.C. Development of home orientation in newly born kittens. Transactions of the New York Academy of Science, 1969, 31, $231-250$.

Scott, J.P. Attachment and separation in dog and man: Theoretical propositions. In H.R. Schaffer (Ed.), The Origins of Human Social Relations. New York: Academic Press, 1971.

Scott, J.P. \& Bronson, F.H. Experimental exploration of the et-epimeletic or care-soliciting behavioral system. In P.H. Leiderman and D. Shapiro (Eds.), Psychobiological approaches to social behavior. Stanford: Stanford University Press, 1964.

Shipley, W.V. The demonstration in the domestic guinea pig of a process resembling classical imprinting. Animal Behavior, 1963, 11, 470-474.

Sluckin, W. Imprinting in guinea pigs. Nature, 1968, 220, 1148 .

Sluckin, W. Early Learning in Man and Animal. Cambridge,

Mass.: Schenkman Publishing Co., 1970. Stern, J.J. \& Bronner, G. Effects of litter size on nursing time and weight of the young in guinea pigs. Psychonomic Science, 1970, 21 (2), 171-172. Stern, J.J. \& Hoffman, B.F. Effects of social isolation until adulthood on maternal behavior in guinea pigs. Psychonomic Science, 1970, 21 (1), 15-16. 
Tobach, E. \& Gold, P.S. Behavior of the guinea pig in an open field. Psychological Reports, 1966, 18, $415-425$.

Zajonc, R.B. Animal Social Behavior. Morristown, New Jersey: General Learning Press, 1972. 